UNIVERSIDADE DE SÃO PAULO

FACULDADE DE ECONOMIA, ADMINISTRAÇÃO E CONTABILIDADE DE RIBEIRÃO PRETO

DEPARTAMENTO DE CONTABILIDADE

PROGRAMA DE PÓS-GRADUAÇÃO EM CONTROLADORIA E CONTABILIDADE

CLARICE GUTIERREZ KITAMURA KAJIMOTO

A suavização do lucro líquido e a persistência das contas de resultado das empresas brasileiras de capital aberto

ORIENTADOR: PROF. DR. SÍLVIO HIROSHI NAKAO

RIBEIRÃO PRETO 
Prof. Dr. Marco Antonio Zago

Reitor da Universidade de São Paulo

Prof. Dr. Dante Pinheiro Martinelli

Diretor da Faculdade de Economia, Administração e Contabilidade de Ribeirão Preto

Prof. Dr. Fabiano Guasti Lima

Chefe de Departamento de Contabilidade 
CLARICE GUTIERREZ KITAMURA KAJIMOTO

\section{A suavização do lucro líquido e a persistência das contas de resultado das empresas brasileiras de capital aberto}

\section{Versão Corrigida}

(A original encontra-se disponível na FEA-RP/USP)

Dissertação apresentada ao Programa de PósGraduação em Controladoria e Contabilidade da Faculdade de Economia, Administração e Contabilidade de Ribeirão Preto da Universidade de São Paulo, para obtenção do título de Mestre em Ciências Contábeis. Versão Original.

Orientador: Prof. Dr. Sílvio Hiroshi Nakao

RIBEIRÃO PRETO 
AUTORIZO A REPRODUÇÃO E DIVULGAÇÃO TOTAL OU PARCIAL DESTE TRABALHO, POR QUALQUER MEIO CONVENCIONAL OU ELETRÔNICO, PARA FINS DE ESTUDO E PESQUISA, DESDE QUE CITADA A FONTE.

Kajimoto, Clarice Gutierrez Kitamura

A suavização do lucro líquido e a persistência das contas de resultado das empresas brasileiras de capital aberto. Ribeirão Preto, 2017.

$$
58 \text { p. : il. ; } 30 \mathrm{~cm}
$$

Dissertação de Mestrado, apresentada à Faculdade de Economia, Administração e Contabilidade de Ribeirão Preto/USP. Orientador: Nakao, Sílvio Hiroshi.

Versão corrigida. A original encontra-se disponível na FEARP/USP.

Palavras chave: persistência do lucro, suavização de resultados, accruals discricionários e qualidade da informação contábil. 
Nome: KAJIMOTO, Clarice Gutierrez Kitamura.

Título: A suavização do lucro líquido e a persistência das contas de resultado das empresas brasileiras de capital aberto

Dissertação apresentada ao Programa de PósGraduação em Controladoria e Contabilidade da Faculdade de Economia, Administração e Contabilidade de Ribeirão Preto da Universidade de São Paulo, para obtenção do título de Mestre em Ciências Contábeis.

Aprovado em:

Prof. Dr. Alfredo Sarlo Neto

Instituição: Universidade Federal do Espírito Santo (UFES)

Julgamento:

Prof. Dr. Jomar Miranda Rodrigues

Instituição: Universidade de Brasília (UnB)

Julgamento:

Profa. Dra. Patrícia de Souza Costa

Instituição: Universidade Federal de Uberlândia (UFU)

Julgamento: 
À minha família com muito amor e carinho! 


\section{AGRADECIMENTOS}

À Deus, que me deu saúde para estudar e ganhar novos conhecimentos a cada dia.

Ao meu orientador Prof. Dr. Sílvio Hiroshi Nakao, que dispôs tempo para me ajudar na pesquisa e por todos os ensinamentos compartilhados comigo.

À minha família, que me apoiou e está do meu lado sempre que preciso.

A todos os meus professores da FEA-RP, que são muito mais que educadores e me ajudaram com conselhos e correções do trabalho, em especial, o Prof. Dr. Marcelo Botelho da Costa de Moraes, que colaborou grandemente para o desenvolvimento desta pesquisa.

À Faculdade de Economia, Administração e Contabilidade - FEARP, pela estrutura que dispõe aos alunos. 


\section{RESUMO}

KAJIMOTO, C. G. K. A suavização do lucro líquido e a persistência das contas de resultado das empresas brasileiras de capital aberto. 2017. $61 \mathrm{f}$. Dissertação (Metrado em Controladoria e Contabilidade) - Faculdade de Economia, Administração e Contabilidade de Ribeirão Preto, Universidade de São Paulo, 2017.

A literatura trata a suavização do lucro líquido como uma das proxies para medir a qualidade da informação contábil (DECHOW; GE; SCHRAND, 2010). Porém, pesquisas sobre suavização do lucro líquido são divergentes em responder se essa suavização aumenta ou diminui a qualidade da informação. Existem trabalhos que testam se o aumento da suavização do lucro líquido aumenta a qualidade da informação por meio da persistência do lucro (TUCKER; ZAROWIN, 2006). Sabe-se, todavia, que os investidores não projetam fluxos de caixa futuros das empresas utilizando somente o lucro líquido, mas as contas de resultado que compõem esse lucro, pois são consideradas relevantes no processo de decisão sobre determinado investimento (BARTON; HANSEN; POWNALL, 2010). Entretanto, desconhecese qual o impacto da suavização sobre as contas de resultado que compõem o lucro líquido. Assim, esta pesquisa procura analisar como o objetivo de suavizar o lucro líquido afeta a persistência das contas de resultado que compõem esse lucro. Nesse sentido, as empresas que fazem parte da amostra foram separadas em empresas que mais e menos suavizam o lucro líquido de acordo com três modelos de suavização encontrados na literatura (LEUZ; NANDA; WYSOCKI , 2003; TUCKER; ZAROWIN, 2006). Posteriormente, foram testadas a persistência das contas de resultado, utilizando o modelo de persistência adaptado de Dechow; Ge e Schrand (2010). Os resultados apontam que as empresas que mais suavizam o lucro líquido possuem contas de resultado mais persistentes em relação às contas das empresas que menos suavizam esse lucro. Além disso, as empresas que mais suavizam o lucro líquido com maior quantidade de accruals discricionários possuem determinadas contas de resultado mais persistentes quando comparadas às empresas que mais suavizam esse lucro com menor quantidade de accruals discricionários. Portanto, os resultados sugerem que o gestor esteja suavizando o lucro artificialmente aumentando a persistência de determinadas contas de resultado, o que caracteriza estas persistências como artificiais. Assim, o investidor que projetar fluxos de caixa de empresas que mais suavizam o lucro líquido com maior quantidade de accruals discricionários poderá ter sua decisão prejudicada.

Palavras-chave: persistência do lucro, suavização de resultados, accruals discricionários e qualidade da informação contábil. 


\begin{abstract}
KAJIMOTO, C. G. K. The net income smoothing and the persistence of the result accounts of Brazilian companies. 2017. 61 f. Dissertação (Metrado em Controladoria e Contabilidade) - Faculdade de Economia, Administração e Contabilidade de Ribeirão Preto, Universidade de São Paulo, 2017.

The literature treats the income smoothing as one of the proxies to measure the earnings quality (DECHOW; GE; SCHRAND, 2010). However, research on the income smoothing diverges in whether this smoothing increases or decreases the earnings quality. There are studies that test whether the increase in income smoothing increases the quality of information through the earnings persistence (TUCKER; ZAROWIN, 2006). It is known, however, that investors do not project future cash flows of companies using only net income, but the profit and loss accounts that make up this profit since they are considered relevant in the decision process on an investment (BARTON; HANSEN; POWNALL, 2010). However, the impact of income smoothing on the income statements that make up net income is not known. Thus, this research seeks to analyze how the objective of smoothing the net profit affects the persistence of the income accounts that compose this profit. In this sense, the companies that are part of the sample were separated into companies that more and less smooth the net profit according to three models of income smoothing found in the literature (LEUZ; NANDA; WYSOCKI , 2003; TUCKER; ZAROWIN, 2006). Subsequently, the persistence of the profit and loss accounts was tested using the persistence model adapted from Dechow; Ge and Schrand (2010). The results show that the companies that smoothed the net profit have more persistent profit and loss accounts in relation to the accounts of the companies that least smooth their profit. In addition, companies that the most smoothed their net income with greater amount of discretionary accruals have more persistent profit and loss accounts when compared to the companies that most smooth their profit with less amount of discretionary accruals. Therefore, the results suggest that it is possible for the manager being artificially smoothing the profit, making certain profit and loss accounts more persistent, which characterizes persistence as artificial. Thus, the investor who projects future cash flow from companies that the most smooth the net income with greater discretionary accruals may have their decision impaired, since the projection of future cash flow may not represent the expected future financial performance of the company.
\end{abstract}

Keywords: earnings persistence, income smoothing, discretionary accruals and earnings quality. 


\section{LISTA DE FIGURAS}

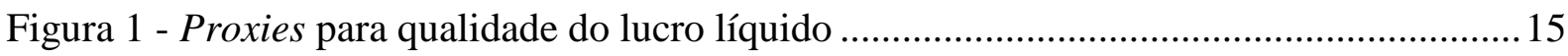

Figura 2 - Tipos de suavização do lucro líquido ................................................................. 17

Figura 3 - Suavização do lucro líquido e o risco percebido pelo investidor ............................ 18

Figura 4 - Persistência dos componentes do lucro líquido ...................................................23 


\section{LISTA DE TABELAS}

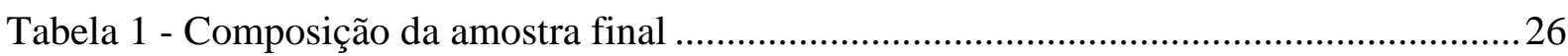

Tabela 2 - Estatística descritiva para o período 2010-2015.................................................... 35

Tabela 3 - Estatística descritiva das empresas que mais suavizam o lucro líquido para o

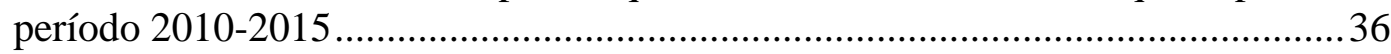

Tabela 4 - Estatística descritiva das empresas que menos suavizam o lucro líquido para o

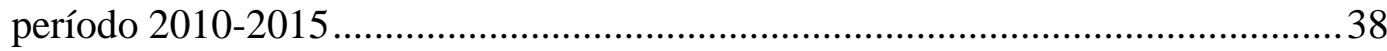

Tabela 5 - Persistência das contas de resultado partindo o modelo de suavização EM1 .........40

Tabela 6 - Persistência das contas de resultado das empresas que mais suavizam com maior e menor quantidade de accruals discricionários ....................................................4 42 


\section{SUMÁRIO}

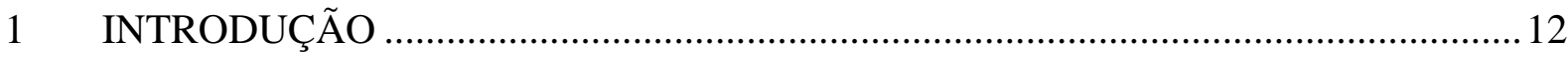

2 REFERENCIAL TEÓRICO E DESENVOLVIMENTO DE HIPÓTESE ..................... 15

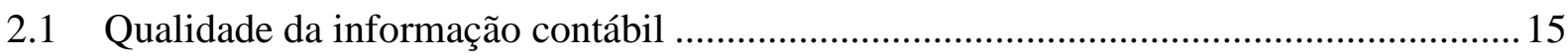

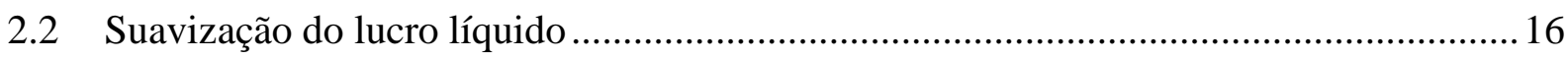

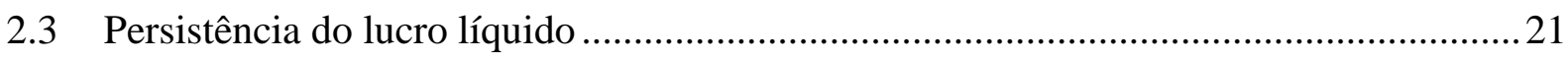

2.4 Suavização do lucro líquido e persistência das contas de resultado ..............................23

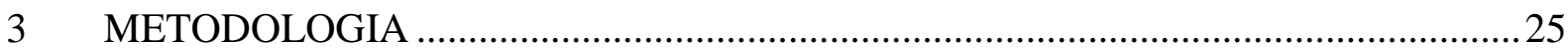

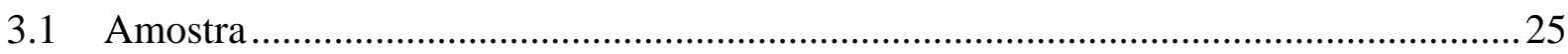

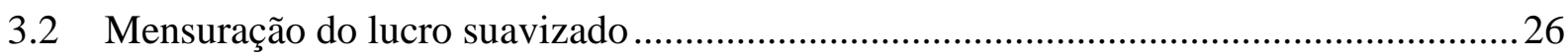

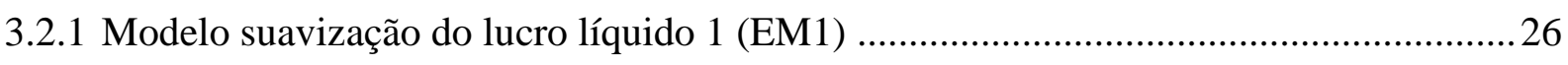

3.2.2 Modelo suavização do lucro líquido 2 (EM2) .......................................................... 27

3.2.3 Modelo de suavização do lucro líquido Tucker e Zarowin (TZ) .................................. 29

3.3 Modelo de persistência das contas de resultado que compõem o lucro líquido ..............30

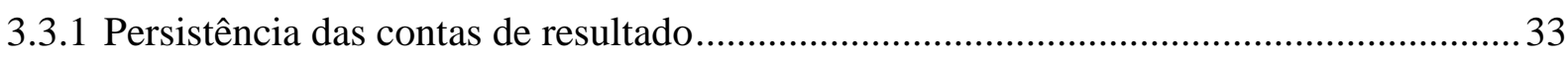

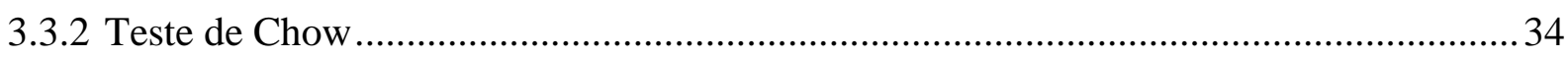

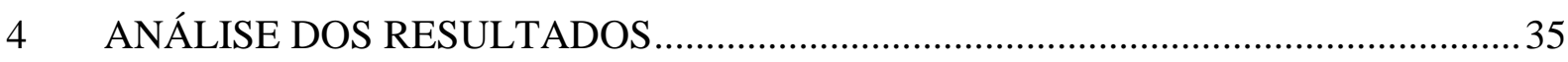

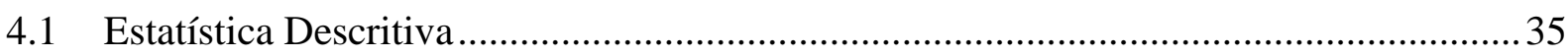

4.2 Persistência das contas de resultado das empresas que mais e menos suavizam o lucro

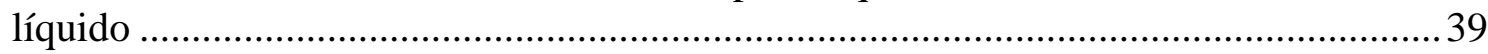

4.3 Persistência das contas de resultado nas empresas que mais suavizam o lucro líquido com maior e menor quantidade de accruals discricionários ...........................................42

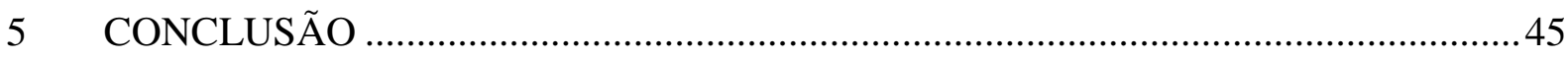

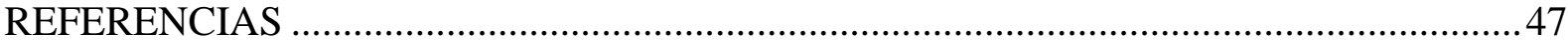

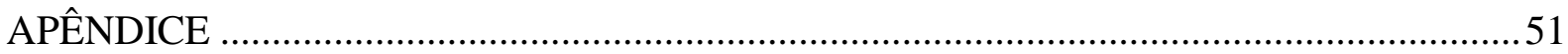




\section{INTRODUÇÃO}

Para Ewert e Wagenhofer (2015), a suavização do lucro líquido aumenta a qualidade da informação contábil porque essa prática traz informação útil para o mercado, e não necessariamente informação enganosa. Além disso, os resultados de Sankar e Subramanyam (2001) apontam que a suavização do lucro líquido pelo gestor tende a melhorar a informação divulgada para o mercado de capitais porque o viés que essa prática impõe ao lucro contábil permite ao gestor incorporar informação privada altamente relevante com antecipação.

Por outro lado, consoante a Ahmed, Neel e Wang (2013), a alta qualidade da informação contábil implica em menor discrição gerencial sobre as escolhas contábeis ou, ainda, menor suavização do lucro líquido pelos gestores. Isso porque, quando o gestor possui liberdade de escolher sobre como e o que divulgar e qual método utilizar para apresentar uma informação aos investidores, ele usará sua discrição sobre as escolhas contábeis baseada em seu próprio interesse. Dessa forma, quando a norma contábil permite ao gestor grande discrição sobre determinadas escolhas contábeis, este pode ser levado a suavizar o lucro de maneira oportunista. Nesse caso, o gestor irá levar em consideração apenas seus interesses, o que faz da informação divulgada menos relevante para a tomada de decisão do investidor (LEUZ; NANDA; WYSOCKI, 2003; FAIRFIELD; WHISENANT; YOHN, 2003; BARTH; LANDSMAN; LANG, 2008; ENOMOTO; KIMURA; YAMAGUCHI, 2015).

Não é possível afirmar que a suavização do lucro líquido aumenta a qualidade da informação contábil pois as pesquisas sobre o assunto apresentam resultados inconclusivos. Ademais, os modelos de suavização do lucro líquido são limitados quanto à separação do que é subjetivo e sujeito ao oportunismo do gestor (DECHOW; SLOAN; SWEENEY, 1995; EWERT; WAGENHOFER, 2015; KOTHARI; LEONE; WASLEY, 2005). Apesar disso, de acordo com Tucker e Zarowin (2006), a suavização do lucro líquido aumenta a persistência desse lucro e, por isso, aumenta a capacidade do investidor em projetar fluxos de caixa futuros da empresa.

Entretanto, a relação entre suavização do lucro e persistência pode ir além da conta de lucro líquido. As contas de resultado que compõem o lucro líquido podem apresentar diferentes níveis de persistência, permitindo efetuar projeções de fluxos de caixa futuros com maior ou menor acurácia. Assim, o objetivo do gestor de suavizar o lucro com accruals discricionários pode afetar os níveis de persistência das contas de resultado. 
Segundo Barton, Hansen e Pownall (2010), o processo de avaliação patrimonial pelo investidor atribui importância às contas de resultado presentes na Demonstração do Resultado do Exercício (DRE) porque estas são capazes de trazer informação futura da empresa de forma rápida e direta. Se o investidor utiliza as contas de resultado para projetar fluxos de caixa, é relevante entender como a suavização do lucro líquido altera o comportamento das contas de resultado. Uma possível maneira para isso é analisar a persistência dessas contas.

Por não estar claro se a suavização do lucro líquido aumenta ou diminui a qualidade da informação contábil e por suspeitar que as contas de resultado podem estar sujeitas à discrição do gestor ao utilizar a suavização para aumentar a persistência dessas contas, a principal motivação desta pesquisa, por conseguinte, é entender como a suavização altera o comportamento das contas de resultado em relação à persistência destas. Uma vez que tais contas são relevantes para o investidor quando este está em um processo de escolha sobre determinado investimento (BARTON; HANSEN; POWNALL, 2010), é possível que a suavização artificial, como meio de manipulação, altere a persistência das contas utilizadas por este para prever fluxos de caixa futuros, impactando negativamente sobre sua decisão de investimento no mercado financeiro.

Assim, cabe a seguinte pergunta de pesquisa: como o objetivo de suavizar o lucro líquido pode afetar a persistência das contas de resultado que compõem esse lucro?

O objetivo desta pesquisa é analisar se a suavização do lucro líquido pelo gestor pode afetar a persistência das contas de resultado nas empresas brasileiras de capital aberto. Assim, são analisadas as contas: Receita líquida, Custo do produto vendido (CPV), Despesa Administrativa, Despesa de venda, Outras receitas operacionais, Outras despesas operacionais, Receita financeira e Despesa financeira.

Para alcançar esse objetivo, as empresas utilizadas na amostra foram separadas entre as que mais suavizam o lucro líquido e menos suavizam o lucro líquido de acordo com três modelos de suavização encontrados na literatura (LEUZ; NANDA; WYSOCKI, 2003; TUCKER; ZAROWIN, 2006). Posteriormente, para cada conta de resultado padronizada pelo modo Z, foi feito o teste de persistência para todas as empresas da amostra utilizando o modelo adaptado de Dechow, Ge e Schrand (2010). 
Por saber que os accruals são separados em accruals discricionários e não discricionários e, ainda, que os accruals discricionários são mais subjetivos que os accruals não discricionários (SLOAN, 1996; XIE, 2001), das empresas que mais suavizam o lucro líquido, separou-se as que mais suavizam com maior quantidade de accruals discricionários e menor quantidade desses accruals. A finalidade dessa separação é verificar como se comporta a persistência das contas de resultado entre tais empresas, pois é possível que a subjetividade presente nos accruals discricionários aumente ainda mais a persistência dessas contas.

Os resultados desses testes, de maneira resumida, são dois. O primeiro resultado mostra que empresas que mais suavizam o lucro líquido possuem contas de resultado mais persistentes que empresas que menos suavizam esse lucro. Além disso, o segundo resultado mostra que as empresas que mais suavizam o lucro com maior quantidade de accruals discricionários apresentam contas de resultado mais persistentes que as empresas que mais suavizam o lucro líquido com menor quantidade desses accruals.

A contribuição deste trabalho está para a literatura de suavização e persistência do lucro líquido. Sendo assim, esta pesquisa contribui com a literatura em questão pois aponta que contas de resultado persistentes não traz, necessariamente, informação útil aos usuários externos das empresas, uma vez que tais contas podem conter accruals discricionários pouco confiáveis que estão ligados à suavização do lucro líquido.

Por outro lado, sob o ponto de vista social, esta pesquisa contribui no sentido de auxiliar o investidor que avalia um investimento, analisando o desempenho financeiro da empresa através das contas de resultado. Sendo assim, cabe ao investidor cautela ao analisar as contas de resultado das empresas que mais suavizam o lucro com maior quantidade de accruals discricionários, pois essas contas podem estar sujeitas à manipulação, o que dá falsa impressão de contas mais persistentes e empresas mais seguras no que tange à análise de investimento no mercado financeiro pelo investidor. 


\section{REFERENCIAL TEÓRICO E DESENVOLVIMENTO DE HIPÓTESE}

\subsection{Qualidade da informação contábil}

Dechow, Ge e Schrand (2010) afirmam que a qualidade do lucro líquido ou lucro contábil está em função do desempenho financeiro da empresa. Por isso, se esse lucro retratar de maneira fidedigna o desempenho econômico de uma empresa, é possível dizer que a contabilidade cumpriu seu papel e, nesse caso, apresentou informação com alta qualidade. Uma vez que a qualidade do lucro líquido não pode ser observada diretamente, para mensurar a qualidade da informação divulgada pela contabilidade são utilizadas proxies. Segundo os autores, essas proxies estão separadas em três categorias, quais sejam propriedades do lucro, capacidade de resposta do investidor sobre o lucro líquido e indicadores externos sobre distorções no lucro. A Figura 1 apresenta as proxies de qualidade do lucro separadas por categorias.

Figura 1 - Proxies para qualidade do lucro líquido

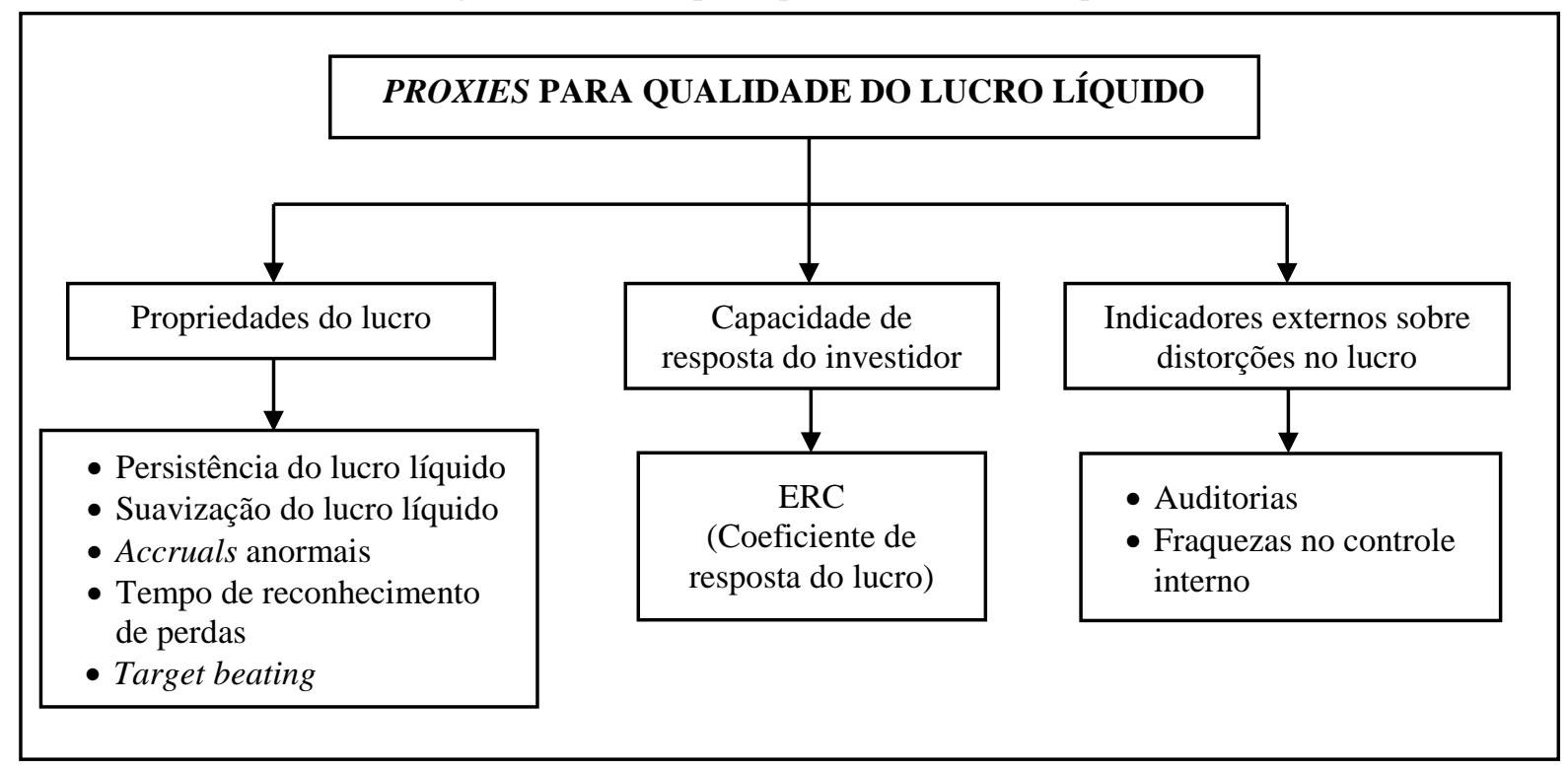

Fonte: adaptado de Dechow, Ge e Schrand (2010)

A primeira categoria representa as propriedades do lucro e é composta por persistência do lucro líquido, suavização do lucro líquido, accruals anormais, tempo de reconhecimento de perdas no resultado e target beating (este último refere-se à manipulação dos resultados contábeis pelos gestores que visam atingir as expectativas dos analistas do mercado financeiro quanto aos resultados esperados por estes). A segunda categoria explica a capacidade de resposta do investidor sobre o lucro contábil que pode ser medida pelo ERC (coeficiente de resposta do 
lucro), em que, quanto maior o valor do coeficiente, maior a capacidade informativa dos componentes desse lucro. A terceira e última categoria proposta compreende os indicadores externos sobre distorções no lucro e, as proxies envolvidas são número de empresas de auditorias, fraquezas no controle externo, etc. Uma das vantagens das proxies dessa última categoria é identificar possíveis problemas relacionados à qualidade do lucro líquido (DECHOW; GE; SCHRAND, 2010).

De acordo com esses autores, quando a empresa divulga um lucro de alta qualidade, ela consegue informar aos investidores sobre as características do desempenho financeiro dela. Então, a informação sobre o lucro se torna relevante para a tomada de decisão de investimento pelos investidores.

A contabilidade é responsável pela divulgação desse desempenho financeiro pois é ela quem converte a informação do desempenho da empresa não observado pelo investidor em lucro líquido. Entretanto, é relevante o entendimento de que o lucro líquido divulgado pela contabilidade pode não ser exatamente igual ao desempenho financeiro desta. Essa diferença pode existir porque a contabilidade está limitada a um conjunto pré-determinado de princípios de mensuração e, também, a estimações e julgamentos que podem levar a erros não intencionais e intencionais. Um exemplo representativo deste último tipo de erro é o gerenciamento de resultado pelo gestor (DECHOW; GE; SCHRAND, 2010, p. 347).

De acordo com Barth; Landsman e Lang (2008), a qualidade da informação contábil tende a aumentar se as normas contábeis diminuir a capacidade do gestor em gerenciar resultados, por exemplo. A discricionariedade oportunista sobre as contas contábeis pelo gestor pode aumentar a diferença entre o lucro líquido e o desempenho financeiro, o que prejudica a qualidade desse lucro. Como alternativa para evitar a baixa qualidade da informação divulgada, os autores acreditam que limitar escolhas de mensuração contábil pode inibir a discrição oportunista exercida pelo gestor. Além disso, outra opção seria o aumento do rigor sobre enforcement, ou seja, fazer com que a lei seja rigorosamente cumprida.

\subsection{Suavização do lucro líquido}

A suavização do lucro é a tentativa dos gestores de uma empresa de reduzir as variações no lucro líquido que ultrapassam o limite considerado normal, ou seja, o lucro pode variar até certo 
nível considerado constante, acima desse nível, o gestor irá recorrer à suavização, manipulando os accruals discricionários presentes no lucro da empresa (BEIDLEMAN, 1973). Esses accruals são gerados, por exemplo, quando no lucro líquido é reconhecida uma receita que ainda não gerou caixa, ou quando um cliente pagou por um produto antecipadamente. Nesse último caso, houve entrada de caixa, mas não houve reconhecimento de receita no resultado (GOVENDIR; WELLS, 2014).

De acordo com Eckel (1981), existem dois tipos de suavização do lucro líquido, sendo a suavização natural e a suavização intencional baseada na vontade do gestor. Na Figura 2, é possível analisar como o autor classifica a suavização desse lucro.

Figura 2 - Tipos de suavização do lucro líquido

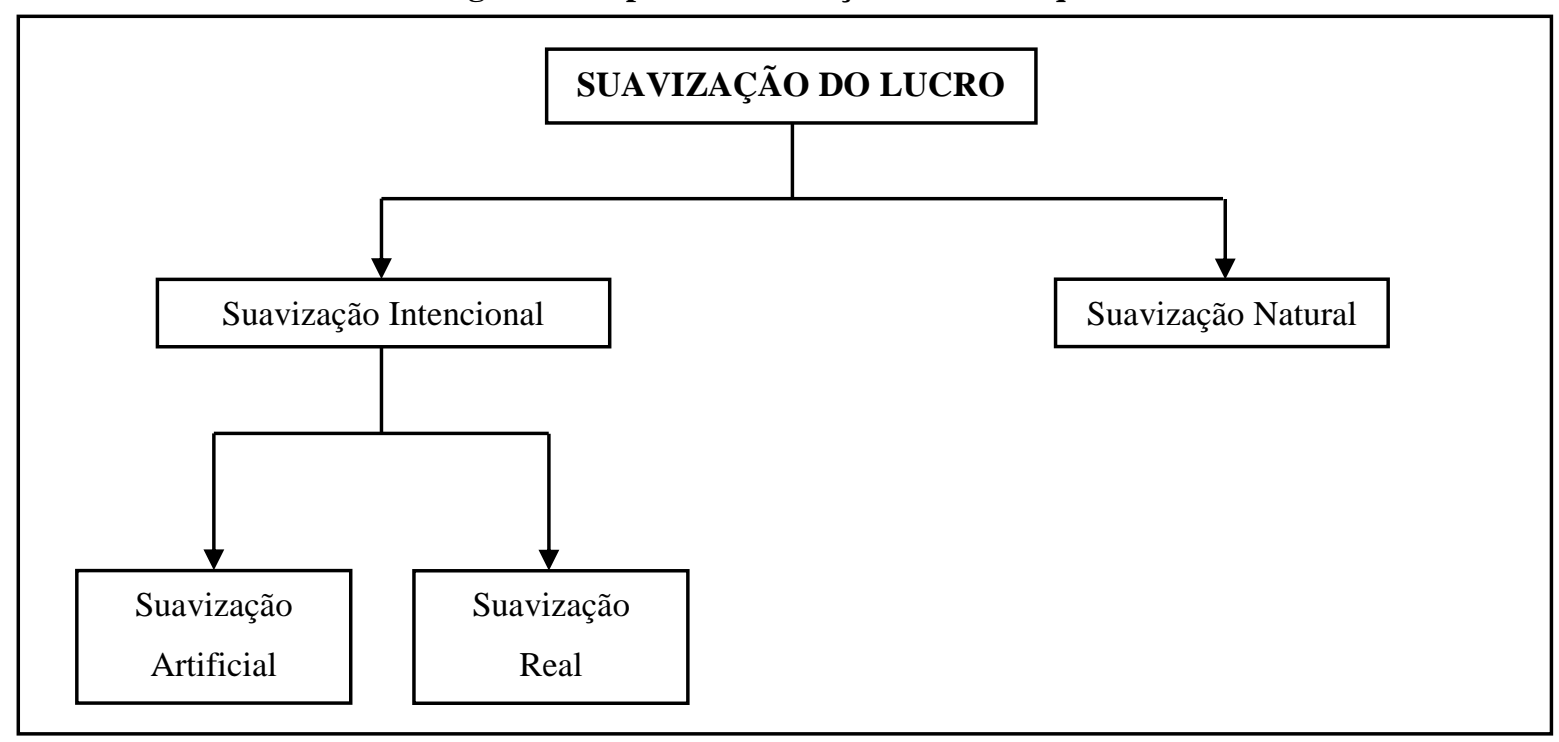

Fonte: adaptado de Eckel (1981)

Segundo o pesquisador, a suavização natural decorre do próprio processo de geração de lucro da empresa, não sendo possível ao gestor manter total controle sobre o processo. Por outro lado, a suavização intencional deriva da discrição que o gestor possui amparado pela norma contábil. Esse tipo de suavização está separado em suavização artificial e suavização real. Esta representa a ação tomada pelo gestor para controlar eventos econômicos, aquela representa a ação tomada pelo gestor para manipular as contas de resultado com a finalidade de deixar o lucro líquido suavizado (ECKEL, 1981).

A suavização do lucro parte de uma escolha contábil discricionária para atingir um determinado objetivo (RONEN; SADAN, 1981). Gordon (1964) afirma que, enquanto couber ao gestor 
escolhas contábeis permitidas pela norma contábil, ele irá suavizar os resultados e, também, a taxa de crescimento do lucro. Sendo assim, quando o lucro corrente é ruim e o lucro futuro esperado é bom, os gestores utilizam parte do lucro futuro esperado para compor o lucro do período que é fraco ou ruim. Ou ainda, quando o lucro do período corrente é bom e a expectativa do lucro futuro esperado é ruim, os gestores evitam divulgar todo o lucro do período corrente para usá-lo posteriormente (DEFOND; PARK, 1997).

A tentativa intencional de amortizar as flutuações do lucro através dos accruals discricionários presentes nos números contábeis é uma prática normal observada nas empresas (BEIDLEMAN, 1973). Graham, Harvey e Rajgopal (2005), ao fazerem uma entrevista com 400 executivos de empresas americanas, descobriram que $78 \%$ dos executivos admitem sacrificar valores do longo prazo para suavizar o lucro. Além disso, aproximadamente $97 \%$ destes preferem suavizar o lucro líquido porque acreditam que, ao suavizar esse lucro, os investidores percebem a empresa menos arriscada, uma vez que a suavização é capaz de alterar o risco percebido pelo investidor, sendo assim, o custo de capital e dívida dessas empresas são diminuídos com tal ação. A Figura 3 mostra como a suavização do lucro líquido pode afetar o risco percebido pelo investidor.

Figura 3 - Suavização do lucro líquido e o risco percebido pelo investidor

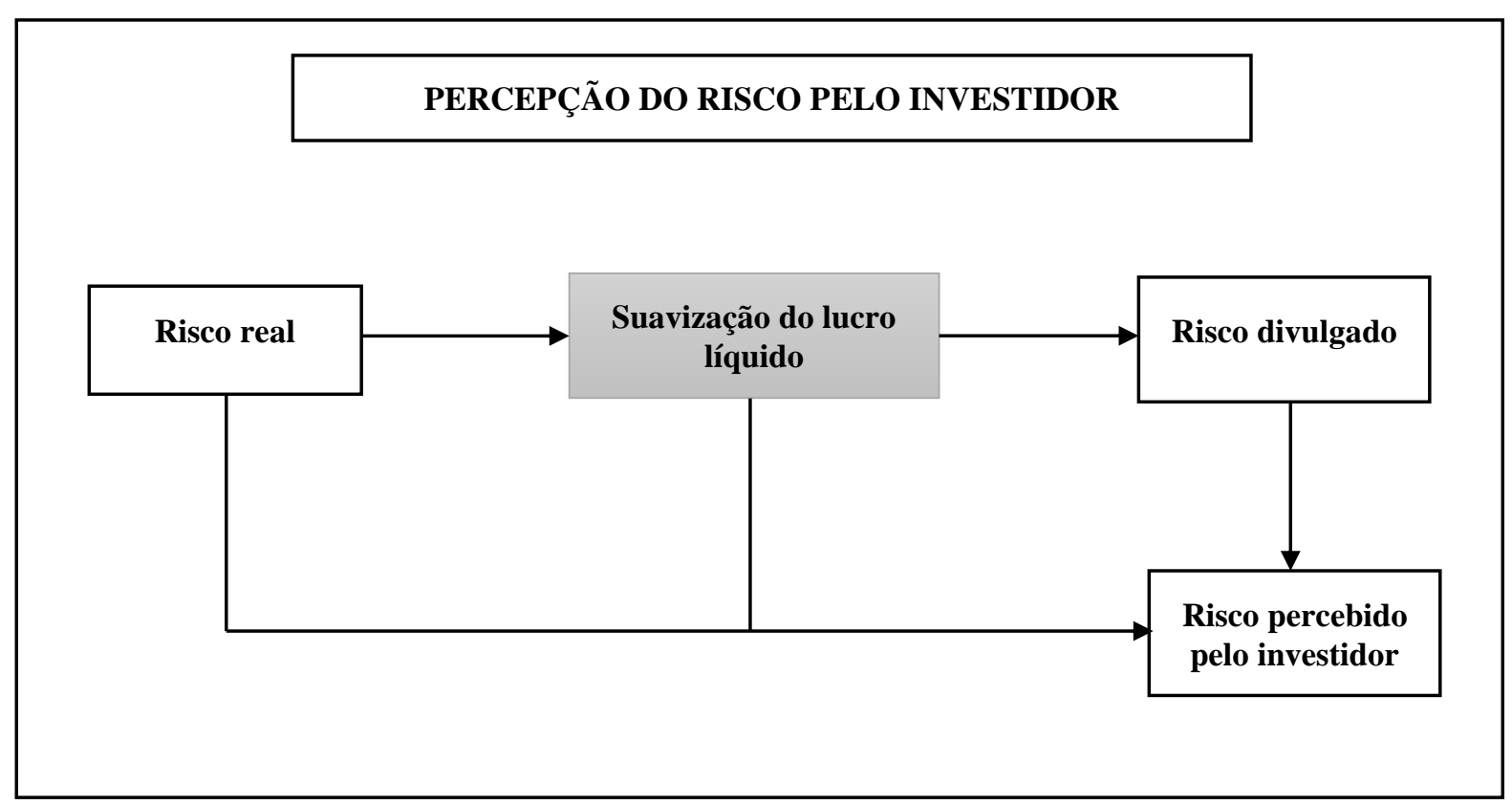

Fonte: Adaptado de Graham, Harvey e Rajgopal (2005)

De acordo com Trueman e Titman (1988), o gestor suaviza o lucro para diminuir a percepção do investidor sobre a variância do lucro líquido da empresa. A finalidade dessa ação é diminuir 
custos de capital e aumentar o valor de mercado desta. Quando o lucro é suavizado, é possível que o investidor consiga estimar o nível futuro de fluxo de caixa esperado com maior precisão. Além disso, a suavização do lucro líquido pode aumentar a confiança do investidor sobre a informação das contas classificadas no longo prazo (KIRSCHENHEITER; MELUMAD, 2005).

A suavização do lucro líquido é um dos tipos existentes de gerenciamento de resultados e, segundo Healy e Wahlen (1999), pode ser interpretada como uma alteração no desempenho econômico da empresa pelo gestor, ou para induzir o investidor ao erro, ou influenciar o resultado contratual. A suavização é, também, utilizada pela literatura como uma das proxies para qualidade da informação contábil em que as flutuações do lucro são amortizadas intencionalmente partindo da escolha do gestor (SCOTT, 2009, p. 405). Esta proxy pode ser analisada sob duas perspectivas, sendo elas: perspectiva da eficiência e perspectiva do oportunismo (FIELDS; LYS; VINCENT, 2001; TUCKER; ZAROWIN, 2006; SCOTT, 2009).

Sob a perspectiva da eficiência, o gestor gerencia o lucro líquido para melhorar a informação dada aos investidores sobre a situação econômica da empresa que não é observada por quem está de fora dela. Por outro lado, sob a perspectiva do oportunismo, o gestor gerencia resultados contábeis na tentativa de levar o investidor ao erro quanto à real situação econômica da empresa (SCOTT, 2009). Nessa última situação, o gerenciamento de resultados prejudica a qualidade da informação contábil, pois o gestor utiliza informação enganosa na tentativa de obter algum benefício para si.

Healy (1985) afirma que o gestor pode suavizar o lucro líquido para ter direito ao bônus dado pela empresa como recompensa pelo seu esforço. Além disso, Fundenberg e Tirole (1995) e DeFond e Park (1997) mostram que o gestor é levado a suavizar o lucro para, também, prevenir contra sua demissão. Assim, o gestor exerce seu poder discricionário, suavizando resultado, para enganar o acionista da empresa na tentativa de que este não perceba que os resultados não são bons como deveriam, evitando a demissão por baixo esforço.

Tomando como base a teoria da agência, é possível que o tipo de contrato estabelecido entre principal e agente determine a motivação deste em suavizar o lucro. De acordo com Lambert (1984), a suavização, de alguma forma, pode trazer benefícios ao principal. Assim, é comum o 
principal desenhar um contrato que incentive o agente a suavizar os resultados da empresa, por exemplo. Afinal, segundo o pesquisador, lucros menos voláteis podem significar que a empresa é menos arriscada como objeto de investimento. Contudo, essa ação pode levar o investidor a fazer uma má avaliação do valor de mercado da empresa, pois esses investidores analisam apenas o lucro, sem levar em consideração os accruals e os componentes do fluxo de caixa. Essas variáveis são importantes na determinação do fluxo de caixa futuro da empresa e, no valor de mercado desta (SLOAN, 1996).

A ação de suavizar o lucro também é observada em empresas que possuem contratos específicos com seus fornecedores. Quando existe um contrato específico entre duas partes de um contrato, é possível que a quebra de contrato traga a uma dessas partes prejuízos. Se uma das partes do contrato apresenta alta volatilidade nos seus resultados, é possível que ela não consiga cumprir com seus compromissos. Essa impossibilidade de cumprir com o contrato pode levar a outra parte a desistir deste. Assim, a suavização do lucro tem o objetivo de sinalizar para outra parte que essa empresa possui capacidade de levar o contrato por um longo tempo porque possui uma situação financeira sólida (DOU; HOPE; THOMAS, 2013). O lucro líquido suavizado, nesse caso, não necessariamente mostra a situação real da empresa, pelo contrário, é uma forma de mascarar a informação.

Segundo Sankar e Subramanyam (2001), Perotti e Wagenhofer (2014) e Ewert e Wagenhofer (2015), a prática de suavizar o lucro líquido aumenta a qualidade da informação contábil porque aumenta capacidade do lucro líquido de explicar retornos futuros da empresa. Quando o usuário da informação possui maior capacidade em fazer previsões sobre o fluxo de caixa futuro através do lucro divulgado, é possível verificar que a informação contábil possui alta qualidade (DECHOW; GE; SCHRAND, 2010). Se a suavização de resultados é capaz de melhorar a previsão sobre os fluxos de caixa futuro e aumentar a qualidade da informação contábil, ela também poderá ser capaz de diminuir a má precificação das empresas pelos investidores no mercado financeiro (PEROTTI; WAGENHOFER, 2014).

Entretanto, é preciso cautela ao analisar a suavização do lucro líquido como forma eficiente de expor informação privada da empresa. Como apontam Dichev et al. (2013) na pesquisa com diretores financeiros, aproximadamente $10 \%$ do gerenciamento de resultado praticado pelas empresas, incluindo suavização de resultados, são para mascarar o desempenho econômico destas. Ou seja, esses números representam claramente o oportunismo do gestor na visão dos 
próprios diretores financeiros que estão ligados diretamente à elaboração e divulgação das contas contábeis. Além disso, é possível que esta seja a primeira pesquisa a apontar em números qual o valor do oportunismo sobre o gerenciamento de resultados; como, também, sobre a suavização do lucro.

\subsection{Persistência do lucro líquido}

Conforme Dechow, Ge e Schrand (2010), empresas que possuem lucro persistente, isto é, um lucro que persiste por um longo tempo sem alterações materiais, possuem informação contábil mais relevante para o investidor na tomada de decisão. Dessa forma, a persistência do lucro líquido torna o lucro uma variável bastante útil na avaliação patrimonial feita pelos investidores. Assim, quanto maior for a persistência do lucro líquido, maior a qualidade da informação e maior a capacidade de resposta do investidor sobre o preço das ações de uma empresa (COLLINS; KOTHARI, 1989).

A persistência do lucro líquido é uma proxy utilizada para medir a qualidade da informação contábil. Essa proxy, apesar de não ser a única utilizada pela literatura para medir a qualidade da informação contábil, tem ganhado destaque em diversos trabalhos (DECHOW; GE; SCHRAND, 2010; HUI; NELSON; YEUNG, 2016). Segundo Dechow (1994), Dechow, Kothari e Watts (1998) e Dechow, Ge e Schrand (2010), quanto maior a persistência do lucro líquido, maior a qualidade da informação trazida pela contabilidade, ou seja, maior a capacidade que o lucro tem de prever fluxos de caixa futuros da empresa. Isso se deve, como apontam Barth, Cram e Nelson (2001) e Govendir e Wells (2014), aos accruals, diferença temporal entre lucro líquido e fluxo de caixa, cuja função é ajustar o reconhecimento do fluxo de caixa operacional ao longo do tempo. Esse ajuste melhora a capacidade do lucro em mensurar o desempenho financeiro da empresa.

A persistência do lucro líquido como uma métrica de qualidade mostra que, se a empresa $\mathrm{X}$ possuir um lucro mais persistente que a empresa Y por um longo tempo, aquela terá o lucro com maior capacidade de medir fluxo de caixa futuro da empresa quando comparada com Y. A capacidade de prever desempenho econômico é maior quanto maior a persistência do lucro líquido. Sendo assim, o lucro do período da primeira empresa é mais útil para medir seu desempenho futuro pois o investidor irá incorrer em menor erro quando decidir fazer avaliação patrimonial dessa empresa (DECHOW; GE; SCHRAND, op. cit., p. 352). 
O estudo sobre persistência do lucro líquido como proxy para qualidade da informação passou a ser discutido na literatura principalmente sobre qual variável é capaz de medir com maior precisão o desempenho futuro da empresa. Sendo assim, quanto maior a precisão em prever fluxo de caixa futuro, maior a relevância da informação no processo de tomada de decisão pelo investidor (DECHOW, 1994; PENMAN; SOUGIANNIS, 1998).

Richardson et al. (2005) mostraram que a persistência do lucro líquido somente diminui quando os accruals existentes no lucro são pouco confiáveis. Se esses accruals possuem alta capacidade de virar caixa no futuro, o lucro líquido é capaz de medir com maior acurácia o desempenho financeiro da empresa e o seu valor de mercado (DECHOW; DICHEV, 2002). Por outro lado, a alta subjetividade dos accruals leva os investidores a não serem capazes de antecipar resultados, o que prejudica a qualidade da informação contábil medida pelo lucro através de sua persistência (DECHOW; DICHEV, 2002; RICHARDSON et al., 2005).

Para Sloan (1996), o lucro líquido possui um componente que é o fluxo de caixa e um outro componente que são os accruals. O fluxo de caixa é o componente que apresenta maior persistência porque é mais objetivo quando comparado aos accruals (SLOAN, 1996; ARTIKIS; PAPANASTASOPOULOS, 2016). Quando no lucro líquido a quantidade de accruals é grande, esse lucro passa a não ser capaz de projetar fluxo de caixa futuro com acurácia porque a subjetividade tende a aumentar. Nesse caso, os resultados projetados por esse lucro podem não refletir a situação econômica real da entidade, prejudicando o processo de tomada de decisão pelo investidor (XIE, 2001). A Figura 4 mostra quais são os componentes do lucro líquido e suas implicações sobre a previsão de fluxo de caixa futuro.

Consoante a Sloan (1996), Xie (2001), Pincus, Rajgopal e Venkatachalam (2007) e Hui, Nelson e Yeung (2016), o investidor não é capaz de observar a diferença de persistência entre os componentes do lucro líquido, sendo eles fluxo de caixa e accruals. Dessa forma, esse investidor comete erros ao precificar as ações das empresas no mercado financeiro pois acredita que a persistência desse lucro reflete os fluxos de caixa futuros que as empresas terão a receber. Entretanto, grande quantidade de accruals discricionários no lucro líquido torna este muito subjetivo, o que compromete a realização desse lucro em caixa. Portanto, os accruals acabam sendo superavaliados pelos investidores por acreditarem que aqueles irão virar caixa no futuro. 
Figura 4 - Persistência dos componentes do lucro líquido

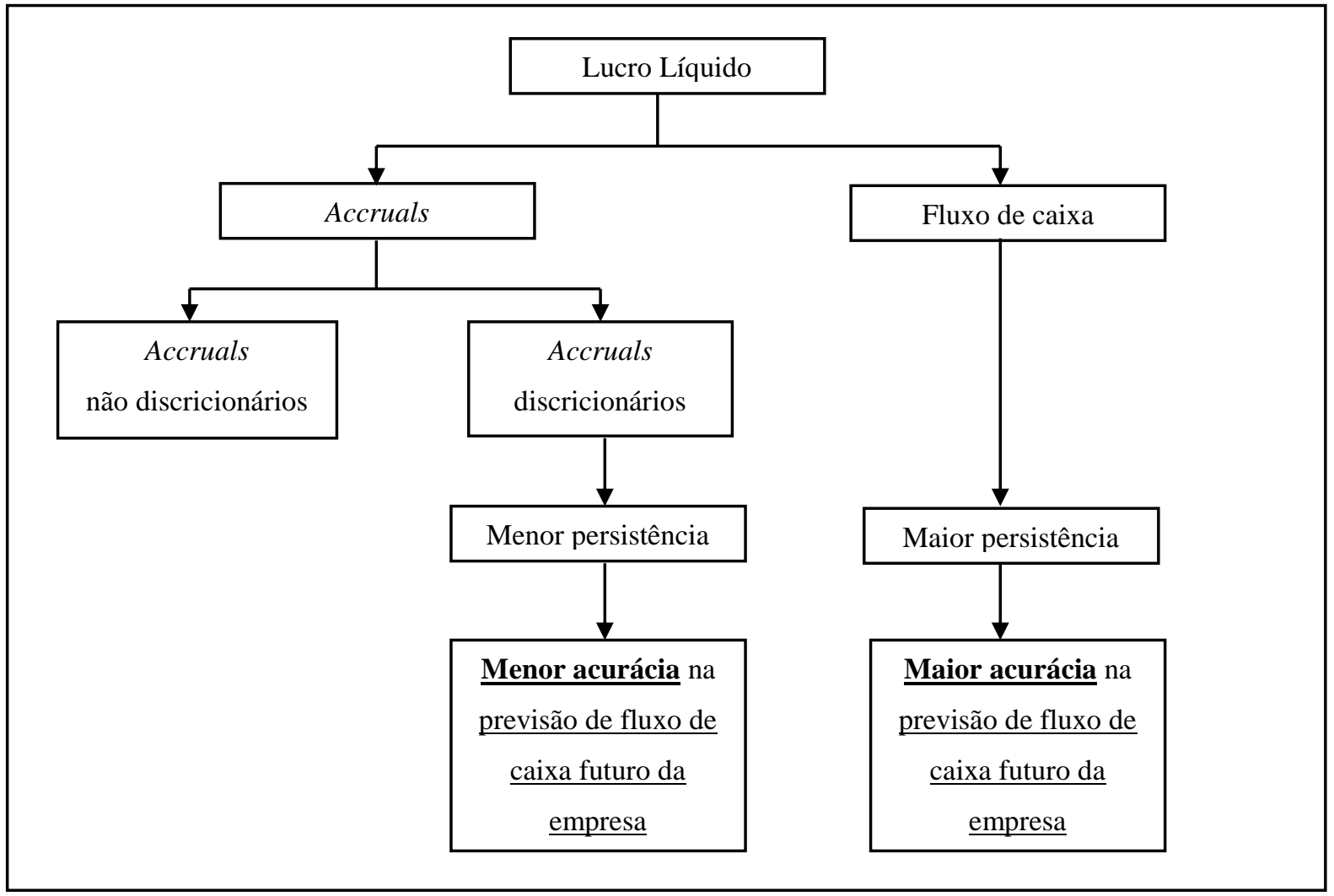

Fonte: Adaptado de Sloan (1996) e Xie (2001)

Segundo Dechow, Richardson e Sloan (2008), a superioridade da persistência do fluxo de caixa está relacionada com o subcomponente desse fluxo de caixa - caixa líquido distribuído aos investidores. Os outros dois subcomponentes do fluxo de caixa, variação do caixa e caixa captado/distribuído aos credores, possuem aproximadamente a mesma persistência atribuída aos accruals existentes no lucro. Com esses resultados, os autores afirmam que é maior a capacidade do investidor em precificar dívida e patrimônio da empresa quando comparado com variações do caixa e accruals.

\subsection{Suavização do lucro líquido e persistência das contas de resultado}

De acordo com Dechow (1994), o lucro líquido é mais persistente que fluxo de caixa porque neste existem accruals capazes de alterar o tempo de reconhecimento do fluxo de caixa no lucro líquido. Além disso, empresas que suavizam o lucro líquido, ora apresentam grande variação nos accruals e baixa variação no fluxo de caixa, ora apresentam grande variação no fluxo de caixa e baixa variação nos accruals (LEUZ; NANDA; WYSOCKI, 2003; ENOMOTO; KIMURA; YAMAGUCHI, 2015). 
Por outro lado, a quantidade de accruals presente no lucro líquido aumenta a subjetividade desse lucro, abrindo espaço para manipulação oportunista, o que leva o investidor ao erro quando analisa o valor patrimonial da empresa. A falta de acesso à persistência desses accruals é o principal fator que leva o investidor a cometer erros ao precificar os ativos da empresa (XIE, 2001).

Accruals e fluxo de caixa, por serem componentes do lucro líquido, são, também, componentes das contas de resultado que compõem esse lucro (SLOAN, 1996; XIE, 2001). Ademais, empresas que mais suavizam o lucro líquido utilizam accruals para diminuir choques do fluxo de caixa no lucro (LEUZ; NANDA; WYSOCKI, 2003; TUCKER; ZAROWIN, 2006; ENOMOTO; KIMURA; YAMAGUCHI, 2015). Segundo Tucker e Zarowin (2006), a suavização do lucro líquido através dos accruals discricionários aumenta a persistência desse lucro, o que melhora a capacidade deste em medir o desempenho financeiro da empresa. Sendo assim, se a suavização do lucro aumenta a persistência deste, é possível que a suavização do lucro líquido aumente, também, a persistência das contas de resultado que compõem esse lucro. Nesse sentido a primeira hipótese da pesquisa é:

$\mathrm{H}_{1}$ : Empresas que mais suavizam o lucro líquido possuem contas de resultado mais persistentes.

Além disso, se a suavização do lucro está relacionada com a quantidade de accruals discricionários presentes nesse lucro, é possível que empresas que mais suavizam o lucro líquido com maior quantidade de accruals discricionários apresentem contas de resultado mais persistentes que empresas que mais suavizam o lucro líquido com menor quantidade de accruals discricionários. Assim, a segunda hipótese desta pesquisa é:

$\mathrm{H}_{2}$ : Empresas que mais suavizam o lucro líquido com maior quantidade de accruals discricionários possuem contas de resultado mais persistentes que empresas que mais suavizam o lucro líquido com menor quantidade de accruals discricionários. 


\section{METODOLOGIA}

\subsection{Amostra}

A amostra utilizada compreende companhias abertas não financeiras com ações listadas na BM\&FBovespa, cujas demonstrações contábeis estão definidas no período de 2010 a 2015. Foram excluídas da amostra instituições financeiras porque a contabilização das contas de resultado é diferente das demais empresas. Além disso, de acordo com Leuz, Nanda e Wysocki (2003) e Salewski e Zülch (2015), a diferença da estrutura do balanço patrimonial das empresas financeiras e seguradoras em relação às demais empresas pode afetar seriamente a comparabilidade das várias empresas envolvidas na análise, o que pode comprometer os resultados que serão analisados.

O período compreende 2010 a 2015 pois foi a partir de 2010 que as empresas passaram a divulgar informações sobre fluxo de caixa, informação necessária para o cálculo dos accruals. Sendo assim, para esta pesquisa, não será necessário o cálculo indireto de fluxo de caixa, o que pode diminuir o viés dos resultados. Ademais, as empresas que compõem a amostra são ativas na bolsa e possuem informação sobre o ativo total para todo o período da análise. Os valores do ativo total são imprescindíveis para os modelos que calculam a suavização do lucro líquido nas empresas, sendo eles os denominadores de dois modelos de suavização empregados nesta pesquisa.

Por fim, optou-se por empresas brasileiras porque o Brasil possui um mercado menos desenvolvido e, por esse motivo, sofre menor pressão por qualidade informacional. Portanto, maior oportunidade para que os gestores suavizem seus resultados, fenômeno que se pretende estudar. Nesse sentido, foi utilizado o banco de dados Economática ${ }^{\circledR}$ para coleta das empresas que compõem a amostra desta pesquisa, pois o software traz informações sobre as demonstrações contábeis financeiras das empresas para o período de análise. A Tabela 1 apresenta detalhes sobre a amostra final. 
Tabela 1 - Composição da amostra final

\begin{tabular}{lcc}
\hline & $\begin{array}{c}\mathbf{N}^{\mathbf{0}} \text { total de empresas } \\
\text { para 2010-2015 }\end{array}$ & $\begin{array}{c}\mathbf{N}^{\mathbf{0}} \text { total de } \\
\text { empresa-ano }\end{array}$ \\
\hline Total de empresas brasileiras cujo tipo de ativo é ação & 590 & 3.540 \\
(-) Empresas não listadas na BM\&FBovespa cujo tipo de ativo é ação & $(213)$ & $(1.278)$ \\
\cline { 2 - 3 } Total de empresas listadas na BM\&FBovespa com ações negociadas & 377 & $(216)$ \\
(-) Instituições financeiras e seguradoras & $(36)$ & 2.046 \\
Total de empresas não financeiras e não seguradoras & 341 & $(276)$ \\
(-) Empresas que possuem ativos totais nulos ou iguais a zero & $(46)$ & $\mathbf{1 . 7 7 0}$ \\
\hline Total de empresas que compõem a amostra final & $\mathbf{2 9 5}$ &
\end{tabular}

Fonte: dados da pesquisa

Nota-se, com a tabela acima, que o número de empresas brasileiras com ação em bolsa é igual a 590, entretanto se considerou apenas empresas listadas na BM\&FBovespa que não sejam instituições financeiras ou seguradoras e que não apresentam ativos totais iguais a zero. Com isso, passou-se para um total de 295 empresas na composição final da amostra ou 1.770 empresa-ano.

\subsection{Mensuração do lucro suavizado}

Esta pesquisa procura calcular três modelos de suavização de resultados que aparecem com frequência na literatura de suavização. Dois deles, suavização do lucro líquido 1 (EM1) e suavização do lucro líquido 2 (EM2), são discutidos no trabalho de Leuz, Nanda e Wysocki (2003) e são utilizados em estudos recentes (PEROTTI; WAGENHOFER, 2014; KHALIL; SIMON, 2014; ENOMOTO; KIMURA; YAMAGUCHI, 2015). O último modelo, suavização do lucro líquido Tucker e Zarowin (TZ), é discutido no trabalho de Tucker e Zarowin (2006) e utilizado para medir a suavização de resultados em alguns trabalhos recentes (PEROTTI; WAGENHOFER, 2014; GAO; ZHANG, 2015; EWERT; WAGENHOFER, 2015).

\subsubsection{Modelo suavização do lucro líquido 1 (EM1)}

Consoante a Leuz, Nanda e Wysocki (2003), o foco desse modelo de suavização do lucro está sobre as escolhas dos gestores quanto à divulgação do relatório financeiro. O modelo dos autores captura o grau de suavização praticado pelos gestores sobre o lucro líquido. Assim, a 
suavização do lucro acontece quando o gestor tenta reduzir a variabilidade do lucro divulgado, alterando os componentes do lucro contábil conhecidos como accruals.

A primeira medida de suavização do lucro líquido adaptado de Leuz, Nanda e Wysocki (2003) é:

$$
E M 1=\frac{s(L O)}{s(F C O)}
$$

Em que:

EM1: Modelo de suavização do lucro líquido 1 para o período de 2010-2015

s: Desvio padrão

LO: Lucro operacional deflacionado pelo ativo total do período anterior

FCO: Fluxo de caixa operacional deflacionado pelo ativo total do período anterior

Portanto, valores baixos de EM1 indicam que, ceteris paribus, o gestor exerce discrição nas contas de resultado para suavizar o lucro líquido (LEUZ; NANDA; WYSOCKI, 2003).

\subsubsection{Modelo suavização do lucro líquido 2 (EM2)}

De acordo com Leuz, Nanda e Wysocki (2003), os gestores também podem usar sua discrição sobre as contas de resultado para esconder choques econômicos sofridos no fluxo de caixa operacional da empresa. Nesse sentido, esses gestores podem antecipar receitas futuras no lucro divulgado do período corrente ou retardar a divulgação de custos nesse mesmo lucro divulgado do período corrente para o período futuro. Essas ações praticadas pelos gestores podem esconder dos usuários da informação contábil o baixo desempenho econômico da empresa no presente período.

Nesses casos, é possível observar que os gestores usam os accruals presentes na contabilização do lucro líquido para amortizar os choques do fluxo de caixa. Isso faz com que a correlação entre accruals e fluxo de caixa tenha natureza negativa, uma vez que esses accruals são a diferença entre lucro líquido e fluxo de caixa (DECHOW, 1994; LEUZ; NANDA; WYSOCKI, 2003). Em um contexto em que os gestores recorrem à suavização de resultados para amortizar os choques sofridos pelo fluxo de caixa, a correlação entre as duas variáveis será altamente 
negativa. Por outro lado, caso os gestores não recorram à prática de suavização de resultados, a correlação entre as variáveis será altamente positiva.

O cálculo dos accruals totais para cada empresa da amostra em um período específico é dado pela seguinte equação:

$$
\text { Accruals totais }=\text { Lucro líquido }- \text { Fluxo de caixa operacional }
$$

As variáveis lucro líquido e fluxo de caixa operacional foram deflacionadas pelo ativo total do período anterior. Sendo assim, a segunda medida de suavização de resultados proposta por Leuz, Nanda e Wysocki (2003) é a seguinte:

$$
E M 2=\rho(\Delta \text { Accruals totais, } \Delta \text { Fluxo de caixa operacional })
$$

Em que:

EM2: Modelo de suavização 2 para o período de 2010-2015

$\rho$ : Correlação

A utilização do período de 6 anos, segundo Tucker e Zarowin (2006), é suficiente para que se possa observar a ação de suavização do lucro nas empresas. Portanto, quanto mais negativo for a correlação dessas variáveis, maior será a prática de suavização desse lucro pelos gestores.

Ambos os modelos EM1 e EM2 não são capazes de separar totalmente accruals discricionários e não discricionários presentes no lucro líquido porque utilizam em seus cálculos os valores dos accruals totais. Assim, é possível que empresas classificadas como as que mais suavizam o lucro líquido tenham contas de resultado cuja suavização é classificada como natural segundo Eckel (1981). Logo, após a separação das empresas que mais e menos suavizam o lucro de acordo com os dois modelos, é possível que a persistência das contas de resultado seja influenciada, também, por accruals não discricionários que não estão relacionados com o poder de escolha do gestor. Nesse caso, a persistência das contas de resultado pode ser maior, mas não necessariamente provocada por influência do gestor, o que não dá aos resultados desta pesquisa capacidade de responder se a variação da persistência sofre alteração quando as contas estão sobre o poder de discrição deste. 


\subsubsection{Modelo de suavização do lucro líquido Tucker e Zarowin (TZ)}

Esse modelo procura medir a suavização do lucro líquido resultante da tentativa do gestor em reduzir variações anormais nesse lucro. Essa ação é possível porque as normas contábeis permitem ao gestor fazer escolhas que melhor representam a situação econômica da empresa (BEIDLEMAN, 1973; TUCKER; ZAROWIN, 2006) ou, ainda, escolhas cujo principal beneficiário é o próprio gestor dado à sua capacidade de discrição oportunista sobre as contas de resultado que compõem o lucro líquido (BARTH; LANDSMAN; LANG, 2008).

O modelo é adaptado dos trabalhos de Leuz, Nanda e Wysocki (2003) e Myers, J., Myers, L. e Skinner (2007) e utilizado por Tucker e Zarowin (2006), como segue:

$$
T Z=\rho(\triangle P A D, \triangle L P D)
$$

Em que:

TZ: Modelo de suavização do lucro líquido baseado em Tucker e Zarowin (2006) para o período 2010-2015

$\rho$ : Correlação

$\triangle$ PAD: Variação Proxy accruals discricionários

$\Delta$ LPD: Variação Lucro pré-discricionário

Quanto menor a correlação entre as variáveis envolvidas, maior o grau de suavização praticado pela empresa. Esse modelo é bastante semelhante ao de Leuz, Nanda e Wysocki (2003), porém o modelo de suavização TZ procura separar os accruals discricionários que se originam do poder de escolha do gestor.

Ademais, o cálculo do lucro pré-discricionário é a diferença entre lucro líquido deflacionado pelo ativo total do período anterior e a proxy para accruals discricionários, como representado na equação abaixo:

$$
L P D=L L-P A D
$$

Em que:

LPD: Lucro pré-discricionário 
LL: Lucro líquido deflacionado pelo ativo do período anterior

PAD: Proxy accruals discricionários

Seguindo Kothari, Leone e Wasley (2005), a estimativa dos accruals discricionários segue a versão cross-sectional do modelo Jones, porém controlado pelo desempenho da empresa, sendo assim:

$$
\begin{aligned}
& T A_{t}=\beta_{0}+\beta_{1}\left(1 / \text { Ativos }_{\text {Totais }}+1\right)+\beta_{2}\left(\Delta \text { Vendas }_{t}\right)+\beta_{3}\left(P P E_{t}\right) \\
& +\beta_{4} R O A_{t}+\varepsilon_{t}
\end{aligned}
$$

Em que:

$\mathrm{TA}_{\mathrm{t}}$ : Accruals totais do período $\mathrm{t}$

$\mathrm{t}$ - 1: período anterior

$\Delta$ Vendas $_{t}$ : Variação das vendas no período t deflacionado pelo ativo total do período anterior $\mathrm{PPE}_{\mathrm{t}}$ : Imobilizado Bruto do período t deflacionado pelo ativo total do período anterior $\mathrm{ROA}_{\mathrm{t}}$ : Retorno sobre os ativos no período $\mathrm{t}$

$\varepsilon_{\mathrm{t}}$ : Erro da regressão no período t (Proxy Accruals Discricionários - PAD)

O termo de erro da regressão representa a proxy de accruals discricionários que será utilizado para obter os valores de TZ e, assim, ser possível separar as empresas que mais suavizam e menos suavizam o lucro líquido.

O retorno sobre o ativo será calculado da seguinte maneira:

$$
R O A=L L / \text { Ativos } \text { Totais }_{t-1}
$$

Em que:

$R O A$ : Retorno sobre o ativo

LL: Lucro líquido

$\mathrm{t}$ - 1: período anterior

3.3 Modelo de persistência das contas de resultado que compõem o lucro líquido 
A persistência do lucro líquido é uma proxy para qualidade da informação contábil. Assim, de acordo com Dechow, Ge e Schrand (2010), quanto maior a persistência do lucro líquido, maior a qualidade desse lucro e maior a relevância da informação contábil para a tomada de decisão pelo investidor. Isto porque, quanto maior a persistência desse lucro, maior a capacidade do investidor em prever fluxo de caixa futuro com maior acurácia.

Além disso, conforme Barton, Hansen e Pownall (2010, p. 754), as contas do meio da demonstração de resultado do exercício (DRE) para um dado período são mais relevantes para o investidor no que tange à estimação do desempenho futuro da empresa. Nesse sentido, tais contas são capazes de mudar a decisão do investidor sobre em quais empresas investir, uma vez que estes acreditam que a projeção de fluxo de caixa corrente através das contas de resultado é capaz de revelar o fluxo de caixa futuro da empresa.

Assim, se as contas do meio da DRE são capazes de impactar na decisão de investimento do investidor e, tendo em vista que o gestor saiba da relevância dessas contas para aquele, é possível que esse gestor manipule essas contas de resultado, alterando sua persistência. De acordo com Tucker e Zarowin (2006), a manipulação baseada na suavização do lucro aumenta a persistência do lucro. Essa ação pode mascarar a percepção do investidor quanto à real situação econômica da empresa, podendo prejudicar financeiramente esses investidores (SLOAN, 1996; BARTH; CRAM; NELSON, 2001).

Após separar as empresas entre as que mais suavizam e menos suavizam o lucro líquido de acordo com os três modelos de suavização citados, o próximo passo será analisar a persistência das contas de resultado que compõem o lucro líquido.

Considerando o Comitê de Pronunciamentos Contábeis (CPC) que emite os pronunciamentos técnicos contábeis e tendo como base o pronunciamento técnico CPC 26 (R1) - Apresentação das Demonstrações Contábeis, as contas que serão analisadas para verificar persistência são: receita líquida, custo do produto vendido (CPV), despesas administrativas, despesas com vendas, outras receitas operacionais, outras despesas operacionais, receita financeira e despesa financeira.

De acordo com o CPC 26 (R1), essas contas compõem o resultado operacional e financeiro, além de serem contas de resultado que irão formar o lucro líquido do período. As despesas 
operacionais que compõem o resultado operacional são contabilizadas pelo método da função da despesa, sendo que esse método é utilizado na demonstração de resultado como forma de agrupar despesas que possuem características semelhantes. Apesar de ser relevante, esse método pode apresentar alocações com viés e considerável subjetividade sobre quais contas irão compor, por exemplo, outras despesas operacionais.

Se existe possibilidade de julgamento sobre as despesas operacionais e o resultado financeiro, é possível que essas contas de resultado sejam suavizadas na intenção de diminuir sua volatilidade e aumentar a sua persistência. Além disso, os accruals presentes no lucro líquido são capazes de diminuir a volatilidade desse lucro e torná-lo suavizado, uma vez que são menos persistentes se comparados ao fluxo de caixa (SLOAN, 1996; ARTIKIS; PAPANASTASOPOULOS, 2016). Portanto, existe a possibilidade dessas contas de resultado serem mais persistentes em empresas que mais suavizam o lucro líquido.

É relevante destacar que todas essas contas de resultado foram padronizadas de modo a ser possível a comparação entre empresas de diferentes tamanhos. Portanto, utilizou-se a padronização z para medir a persistência de cada conta de resultado, em que a diferença entre o valor observado da conta e sua média é dividido pelo desvio padrão da amostra para cada conta em um período que compreende os anos de 2010 a 2015. Assim:

$$
Z=\frac{x-\bar{x}}{s}
$$

Em que:

$\mathrm{x}$ : conta de resultado utilizada para o cálculo da persistência

$\bar{x}$ : média da conta de resultado utilizada para o cálculo da persistência

s: desvio padrão da conta de resultado utilizada para o cálculo da persistência

A seguir, será apresentado o modelo de persistência utilizado para cada conta de resultado. Os parâmetros foram estimados por meio do método de mínimos quadrados ordinários utilizando uma regressão linear múltipla em cross-section adaptado para as contas de resultado segundo o modelo de Dechow, Ge e Schrand (2010). 


\subsubsection{Persistência das contas de resultado}

Para medir a persistência das contas de resultado, será utilizado o modelo de regressão linear múltipla em cross-section proposto por Dechow, Ge e Schrand (2010) e adaptado para cada conta de resultado a ser analisada. Assim, a persistência é calculada da seguinte forma:

$$
X_{t+1}=\alpha+\beta_{1} X_{t}+\beta_{2} S U V+\beta_{3} X_{t} \cdot S U V+\varepsilon_{t}
$$

Em que:

X: conta de resultado

SUV: Variável dummy para suavização

t: ano

$\varepsilon$ : erro da regressão

As contas de resultado são representadas pela variável X e são: "receita líquida, CPV, despesa administrativa, despesa de vendas, outras receitas/despesas operacionais, receita financeira e despesa financeira". Portanto, serão oito contas de resultados utilizadas para verificação da persistência.

Outra variável do modelo é a SUV, que representa dummy igual a 1 para as empresas que mais suavizam o lucro líquido, e zero para empresas que menos suavizam o lucro líquido. Nesta pesquisa, optou-se por considerar as empresas que mais suavizam o lucro líquido as mesmas que estão somadas no primeiro quartil de cada modelo de suavização calculado. Por outro lado, optou-se por considerar as empresas que menos suavizam o lucro líquido como aquelas que estão somadas ao quarto quartil dos modelos de suavização utilizados. Além disso, para as empresas que mais suavizam o lucro líquido com maior e menor quantidade de accruals discricionários, a dummy passará a ser igual a 1 e 0 , respectivamente.

Ao separar as empresas que mais suavizam com maior e menor quantidade de accruals discricionários, as empresas serão separadas respeitando a ordem dos modelos de suavização EM1, seguido por TZ ou EM2, seguido por TZ. Assim, as empresas classificadas como empresas que mais suavizam o lucro líquido serão as que compõem os menores valores de EM1 ou EM2 limitados pela mediana dos valores. Posteriormente à separação das empresas que mais suavizam o lucro líquido, as empresas que mais suavizam esse lucro terão os valores de TZ 
calculados e as empresas que mais suavizam o lucro líquido com maior quantidade de accruals discricionários serão as que compõem o $1^{\circ}$ quartil ordenado pelos valores de TZ. Por outro lado, as empresas que mais suavizam o lucro líquido com menor quantidade de accruals discricionários serão as empresas que compõem o $4^{\circ}$ quartil ordenado pelos valores de TZ.

\subsubsection{Teste de Chow}

Para verificar se as empresas que mais suavizam o lucro líquido de fato apresentam contas de resultado mais persistentes, é necessário realizar um teste de estabilidade estrutural. O teste de Chow permite verificar se os parâmetros do modelo de regressão apresentam mudança estrutural (GUJARATI, 2011). O modelo para o teste de Chow é o seguinte:

$$
F=\frac{\left(S Q R_{R}-S Q R_{S R}\right) / k}{\left(S Q R_{S R}\right) /\left(n_{1}+n_{2}-2 k\right)} \sim F_{\left[k,\left(n_{1}+n_{2}-2 k\right)\right]}
$$

Em que:

F: razão F

$\mathrm{SQR}_{\mathrm{R}}$ : Soma restrita dos quadrados dos resíduos

SQRSR: Soma sem restrição dos quadrados dos resíduos

n: número de observações

k: número de parâmetros estimados

A hipótese nula desse teste é que não há mudança estrutural. Portanto, segundo Gujarati (2011), se o valor de $\mathrm{F}$ calculado pela equação acima for maior que o $\mathrm{F}$ crítico da tabela $\mathrm{F}$ no nível de significância escolhido, rejeita-se a hipótese nula de estabilidade dos parâmetros e se conclui que existe diferença entre, no caso desta pesquisa, a persistência das contas de resultado das empresas que mais suavizam o lucro líquido comparado com as empresas que menos suavizam esse lucro, ou empresas que mais suavizam o lucro líquido com maior quantidade de accruals discricionários e menor quantidade desses accruals. 


\section{ANÁLISE DOS RESULTADOS}

\subsection{Estatística Descritiva}

A Tabela 2 apresenta a estatística descritiva das variáveis utilizadas no trabalho para o período de 2010 a 2015. A tabela mostra os valores da média, desvio padrão, valor mínimo, mediana e valor máximo das variáveis. As variáveis EM1, EM2 e TZ foram utilizadas para calcular a suavização do lucro líquido de cada empresa e para, posteriormente, separar as empresas que mais suavizam o lucro líquido das empresas que menos suavizam o lucro líquido. Além disso, essa tabela também apresenta a estatística descritiva de cada conta de resultado analisada.

Tabela 2 - Estatística descritiva para o período 2010-2015

\begin{tabular}{lccccc}
\hline & Média & Desvio Padrão & Mínimo & Mediana & Máximo \\
\hline EM1 & 2,976 & 1,062 & 0,016 & 1,062 & 101,205 \\
EM2 & $-0,614$ & 0,463 & $-1,000$ & $-0,808$ & 1,000 \\
TZ & $-0,848$ & 0,372 & $-1,000$ & $-0,991$ & 1,000 \\
Receita líquida & 0,014 & 1,048 & $-0,245$ & $-0,206$ & 17,662 \\
CPV & 0,015 & 1,056 & $-0,236$ & $-0,202$ & 18,444 \\
Despesa administrativa & $-0,001$ & 0,960 & $-0,178$ & $-0,144$ & 21,784 \\
Despesa de venda & 0,016 & 1,054 & $-0,264$ & $-0,246$ & 12,951 \\
Outras receitas operacionais & $-0,001$ & 1,015 & $-0,245$ & $-0,236$ & 15,781 \\
Outras despesas operacionais & 0,004 & 1,068 & $-0,087$ & $-0,086$ & 31,375 \\
Receita financeira & $-0,007$ & 0,835 & $-0,126$ & $-0,112$ & 19,730 \\
Despesa financeira & 0,012 & 1,030 & $-0,205$ & $-0,176$ & 25,952 \\
\hline
\end{tabular}

Em1 é igual a divisão do desvio padrão do lucro operacional e desvio padrão do fluxo de caixa operacional, em que os menores valores representam empresas que suavizam mais o lucro líquido para o período de 2010-2015 (LEUZ; NANDA; WYSOCKI, 2003). Em2 é igual a correlação da variação de accruals totais e variação de fluxo de caixa das operações, em que os menores valores representam as empresas que mais suavizam o lucro líquido para o período de 2010-2015 (LEUZ; NANDA; WYSOCKI, 2003; TUCKER; ZAROWIN, 2006). TZ é igual a correlação da variação da proxy para accruals discricionários e variação do lucro pré-discricionário, em que os menores valores representam as empresas que mais suavizam o lucro líquido para o período de 2010-2015 (LEUZ; NANDA; WYSOCKI, 2003; TUCKER; ZAROWIN, 2006). Os valores apresentados de receita líquida, CPV, despesa administrativa, despesa com venda, outras receitas operacionais, outras despesas operacionais, receita financeira e despesa financeira foram padronizadas por z-score e representam quantos desvios-padrões cada variável está distante da sua média.

Como mostra a Tabela 2, o valor médio de EM1 é aproximadamente igual a 2,976. Além disso, para EM2 e TZ, os valores médios são aproximadamente iguais a -0,614 e -0,848, nessa ordem. Portanto, de acordo com os três modelos de suavização, empresas que suavizam mais o lucro 
líquido apresentam os menores valores de EM1, EM2 e TZ. Por outro lado, empresas que menos suavizam o lucro líquido apresentam os maiores valores de EM1, EM2 e TZ.

Ainda de acordo com a Tabela 2, todas as variáveis que compõem o lucro líquido apresentam valores expressivos para análise do desvio padrão, isto porque essas contas apresentam um amplo alcance entre os valores de mínimo e máximo. Nesse sentido, a variabilidade existente em relação à média mostra que as empresas que compõem a amostra possuem características diferentes para cada conta de resultado apresentada.

A Tabela 3 apresenta as empresas que mais suavizam o lucro de acordo com os modelos de suavização, EM1, EM2 e TZ. Essa tabela traz a estatística descritiva das contas de resultado que serão analisadas. O número de observações das empresas que mais suavizam o lucro líquido é 444 empresa-ano.

Tabela 3 - Estatística descritiva das empresas que mais suavizam o lucro líquido para o período 2010-2015 (continua)

\begin{tabular}{|c|c|c|c|c|c|}
\hline & Média & Desvio Padrão & Mínimo & Mediana & Máximo \\
\hline \multicolumn{6}{|l|}{ EM1 } \\
\hline Receita líquida & $-0,040$ & 0,499 & $-0,245$ & $-0,205$ & 3,430 \\
\hline CPV & $-0,025$ & 0,546 & $-0,236$ & $-0,199$ & 3,614 \\
\hline Despesa administrativa & $-0,075$ & 0,193 & $-0,178$ & $-0,138$ & 0,878 \\
\hline Despesa de venda & 0,062 & $1, \mathbf{0 3 3}$ & $-0,264$ & $-0,238$ & 9,095 \\
\hline Outras receitas operacionais & $-0,065$ & 0,651 & $-0,245$ & $-0,232$ & 7,430 \\
\hline Outras despesas operacionais & $-0,058$ & 0,115 & $-0,087$ & $-0,086$ & 1,870 \\
\hline Receita financeira & $-0,076$ & 0,099 & $-0,126$ & $-0,111$ & 0,842 \\
\hline Despesa financeira & $-0,086$ & 0,255 & $-0,205$ & $-0,177$ & 2,171 \\
\hline \multicolumn{6}{|l|}{ EM2 } \\
\hline Receita líquida & 0,093 & 0,841 & $-0,245$ & $-0,175$ & 8,405 \\
\hline CPV & 0,118 & 0,969 & $-0,236$ & $-0,172$ & 9,971 \\
\hline Despesa administrativa & $-0,037$ & 0,250 & $-0,178$ & $-0,128$ & 1,903 \\
\hline Despesa de venda & 0,242 & 1,410 & $-0,264$ & $-0,225$ & 9,668 \\
\hline Outras receitas operacionais & $-0,032$ & 0,730 & $-0,245$ & $-0,228$ & 7,430 \\
\hline Outras despesas operacionais & $-0,053$ & 0,121 & $-0,087$ & $-0,085$ & 1,870 \\
\hline Receita financeira & $-0,033$ & 0,276 & $-0,126$ & $-0,103$ & 4,170 \\
\hline Despesa financeira & $-0,022$ & 0,424 & $-0,205$ & $-0,169$ & 5,166 \\
\hline \multicolumn{6}{|l|}{$\mathbf{T Z}$} \\
\hline Receita líquida & 0,125 & 0,825 & $-0,245$ & $-0,129$ & 8,405 \\
\hline $\mathrm{CPV}$ & 0,148 & 0,942 & $-0,236$ & $-0,124$ & 9,971 \\
\hline
\end{tabular}


Tabela 3 - Estatística descritiva das empresas que mais suavizam o lucro líquido para o período 20102015

\begin{tabular}{lccccc}
\hline Despesa administrativa & $-0,018$ & 0,285 & $-0,178$ & $-0,106$ & (conclusão) \\
Despesa de venda & $\mathbf{0 , 3 0 6}$ & $\mathbf{1 , 4 5 1}$ & $\mathbf{- 0 , 2 6 4}$ & $\mathbf{- 0 , 2 0 4}$ & $\mathbf{9 , 6 6 8}$ \\
Outras receitas operacionais & 0,047 & 1,167 & $-0,245$ & $-0,228$ & 15,781 \\
Outras despesas operacionais & $-0,048$ & 0,110 & $-0,087$ & $-0,084$ & 0,826 \\
Receita financeira & $-0,015$ & 0,295 & $-0,126$ & $-0,102$ & 4,170 \\
Despesa financeira & 0,036 & 0,541 & $-0,205$ & $-0,157$ & 5,346 \\
\hline
\end{tabular}

Em1 é igual a divisão do desvio padrão do lucro operacional e desvio padrão do fluxo de caixa operacional, em que os menores valores representam empresas que suavizam mais o lucro líquido para o período de 2010-2015 (LEUZ; NANDA; WYSOCKI, 2003). Em2 é igual a correlação da variação de accruals totais e variação de fluxo de caixa das operações, em que os menores valores representam as empresas que mais suavizam o lucro líquido para o período de 2010-2015 (LEUZ; NANDA; WYSOCKI, 2003; TUCKER; ZAROWIN, 2006). TZ é igual a correlação da variação da proxy para accruals discricionários e variação do lucro pré-discricionário, em que os menores valores representam as empresas que mais suavizam o lucro líquido para o período de 2010-2015 (LEUZ; NANDA; WYSOCKI, 2003; TUCKER; ZAROWIN, 2006). Os valores apresentados de receita líquida, CPV, despesa administrativa, despesa com venda, outras receitas operacionais, outras despesas operacionais, receita financeira e despesa financeira foram padronizadas por z-score e representam quantos desvios-padrões cada variável está distante da sua média.

Consoante à Tabela 3, para as empresas que mais suavizam o lucro líquido de acordo com os três modelos de suavização utilizados, a conta de resultado que apresenta maior variabilidade em relação à média é a despesa de venda para os três modelos. Essa tabela aponta que as empresas que compõem a amostra das que mais suavizam o lucro líquido possuem características distintas quanto à despesa de venda, levando a média a apresentar valores superiores em comparação com a mediana para cada modelo. Além disso, para o modelo de suavização TZ, o desvio padrão para conta de resultado despesa de venda foi de 1,451, maior valor de desvio padrão encontrado para esta conta em relação aos três modelos analisados. Com isso, a média apresentou valor igual a 0,306 que é superior ao valor da mediana de -0,204. Assim, se chegou a um valor de mínimo e máximo respectivamente de -0,264 e 9,668, o que mostra a dimensão da variação para essa conta de resultado.

A Tabela 4 apresenta a estatística descritiva das empresas que menos suavizam o lucro líquido de acordo com os modelos de suavização utilizados. Assim, na Tabela 4, estão os valores da média, mediana, desvio padrão, mínimo e máximo valor das contas de resultado que compõem o lucro líquido. O número de observações das empresas que menos suavizam o lucro líquido é 444 empresa-ano. 
Tabela 4 - Estatística descritiva das empresas que menos suavizam o lucro líquido para o período 20102015

\begin{tabular}{|c|c|c|c|c|c|}
\hline & Média & $\begin{array}{l}\text { Desvio } \\
\text { Padrão }\end{array}$ & Mínimo & Mediana & Máximo \\
\hline \multicolumn{6}{|l|}{ EM1 } \\
\hline Receita líquida & $-0,166$ & 0,188 & $-0,245$ & $-0,235$ & 0,885 \\
\hline $\mathrm{CPV}$ & $-0,159$ & 0,182 & $-0,236$ & $-0,229$ & 0,948 \\
\hline Despesa administrativa & $-0,077$ & 0,544 & $-0,178$ & $-0,163$ & 7,087 \\
\hline Despesa com venda & $-0,203$ & 0,147 & $-0,264$ & $-0,260$ & 0,924 \\
\hline Outras receitas operacionais & 0,011 & 0,996 & $-0,245$ & $-0,236$ & 13,122 \\
\hline Outras despesas operacionais & $-0,043$ & 0,178 & $-0,087$ & $-0,086$ & 2,445 \\
\hline Receita financeira & 0,044 & 1,498 & $-0,126$ & $-0,120$ & 19,730 \\
\hline Despesa financeira & $-0,018$ & 1,035 & $-0,205$ & $-0,189$ & 13,994 \\
\hline \multicolumn{6}{|l|}{ EM2 } \\
\hline Receita líquida & $-0,134$ & 0,570 & $-0,245$ & $-0,236$ & 5,234 \\
\hline $\mathrm{CPV}$ & $-0,143$ & 0,442 & $-0,236$ & $-0,229$ & 4,758 \\
\hline Despesa administrativa & $-0,072$ & 0,564 & $-0,178$ & $-0,161$ & 7,087 \\
\hline Despesa com venda & $-0,209$ & 0,127 & $-0,264$ & $-0,264$ & 0,624 \\
\hline Outras receitas operacionais & $-0,019$ & 0,871 & $-0,245$ & $-0,240$ & 8,895 \\
\hline Outras despesas operacionais & $-0,013$ & 0,367 & $-0,087$ & $-0,086$ & 4,092 \\
\hline Receita financeira & $\mathbf{0 , 0 7 6}$ & 1,576 & $-0,126$ & $-0,119$ & 19,730 \\
\hline Despesa financeira & 0,085 & 1,760 & $-0,205$ & $-0,189$ & 25,952 \\
\hline \multicolumn{6}{|l|}{ TZ } \\
\hline Receita líquida & $-0,216$ & 0,074 & $-0,245$ & $-0,245$ & 0,289 \\
\hline CPV & $-0,207$ & 0,080 & $-0,236$ & $-0,236$ & 0,365 \\
\hline Despesa administrativa & $-0,105$ & 0,540 & $-0,178$ & $-0,173$ & 7,087 \\
\hline Despesa com venda & $-0,233$ & 0,112 & $-0,264$ & $-0,264$ & 0,624 \\
\hline Outras receitas operacionais & $-0,016$ & 1,062 & $-0,245$ & $-0,244$ & 15,747 \\
\hline Outras despesas operacionais & $-0,052$ & 0,181 & $-0,087$ & $-0,087$ & 2,445 \\
\hline Receita financeira & $\mathbf{0 , 0 2 8}$ & 1,497 & $-0,126$ & $-0,123$ & 19,730 \\
\hline Despesa financeira & $-0,053$ & 1,024 & $-0,205$ & $-0,202$ & 13,994 \\
\hline
\end{tabular}

Em1 é igual a divisão do desvio padrão do lucro operacional e desvio padrão do fluxo de caixa operacional, em que os menores valores representam empresas que suavizam mais seus resultados para o período de 2010-2015 (LEUZ; NANDA; WYSOCKI, 2003). Em2 é igual a correlação da variação de accruals totais e variação de fluxo de caixa das operações, em que os menores valores representam as empresas que mais suavizam seus resultados para o período de 2010-2015 (LEUZ; NANDA; WYSOCKI, 2003; TUCKER; ZAROWIN, 2006). TZ é igual a correlação da variação da proxy para accruals discricionários e variação do lucro pré-discricionário, em que os menores valores representam as empresas que mais suavizam seus resultados para o período de 2010-2015 (LEUZ; NANDA; WYSOCKI, 2003; TUCKER; ZAROWIN, 2006). Os valores apresentados de receita líquida, CPV, despesa administrativa, despesa com venda, outras receitas operacionais, outras despesas operacionais, receita financeira e despesa financeira foram padronizadas por z-score e representam quantos desvios-padrões cada variável está distante da sua média 
Observa-se que, ao contrário das empresas que mais suavizam o lucro líquido, as empresas que menos suavizam o lucro líquido apresentam maior variabilidade nas contas de resultado, receita financeira e despesa financeira. Portanto, os desvios padrão dessas contas de resultado são maiores em comparação com as demais contas de resultado. Além disso, dentre as duas contas de resultado que mais apresentam variabilidade, cabe destacar que o desvio padrão para despesa financeira separado pelo modelo de suavização EM2 apresenta o maior valor, chegando a 1,760. Com isso, sua média é de 0,085 , valor maior que o apresentado pela mediana que é de $-0,189$, o que mostra um valor mínimo e máximo de respectivamente -0,205 e 25,952.

Tomadas em conjunto, essas duas últimas tabelas apresentam resultados que sugerem duas interpretações. A primeira é que, independentemente do modelo de suavização, as contas com maior variação são as mesmas dentro de cada grupo e diferentes entre esses grupos. A segunda é que, como a despesa de venda está ligada às atividades operacionais e as contas receitas e despesas financeiras às contas de resultado financeiro, os resultados estatísticos sugerem que as empresas que mais suavizam o lucro líquido possuem atividades com resultados menos similares entre si. Isso não sugere necessariamente suavização do lucro líquido, mas pode indicar que a despesa de venda representa uma particularidade das empresas que mais suavizam o lucro. O mesmo ocorre com as empresas que menos suavizam o lucro, estas apresentaram maior variância nos resultados financeiros. Como a conta de despesa de vendas faz parte do processo de comprar e vender, ao contrário dos resultados financeiros, é possível afirmar que os dois grupos possuem características diferentes na composição do lucro líquido.

\subsection{Persistência das contas de resultado das empresas que mais e menos suavizam o lucro líquido}

A Tabela 5 apresenta os resultados das persistências das contas de resultado para o período de 2010 a 2015 de acordo com o modelo de regressão linear adaptado de Dechow, Ge e Schrand (2010) para as empresas que mais e menos suavizam o lucro líquido de acordo com o modelo de suavização EM1 de Leuz, Nanda e Wysocki (2003). Cada coluna dessa tabela representa uma regressão linear múltipla em cross-section. 
Tabela 5 - Persistência das contas de resultado partindo do modelo de suavização EM1

\begin{tabular}{|c|c|c|c|c|}
\hline & Receita Líquida & CPV & $\begin{array}{c}\text { Despesa } \\
\text { Administrativa }\end{array}$ & $\begin{array}{c}\text { Despesa de } \\
\text { Venda }\end{array}$ \\
\hline$\overline{X_{t}}$ & $0,851 * * *$ & $1,127 * * *$ & $0,622 * * *$ & $0,785 * * *$ \\
\hline SUV & $0,031 * * *$ & 0,011 & $0,052 * * *$ & $0,044 * * *$ \\
\hline $\mathrm{X}_{\mathrm{t}} \mathrm{SUV}$ & $0,153 * * *$ & 0,046 & $\mathbf{0 , 3 1 4} * * *$ & $0,185^{* * *}$ \\
\hline Interseção & $-0,031 * * *$ & $0,032^{* *}$ & $-0,056^{* * *}$ & $-0,048 * * *$ \\
\hline $\mathrm{N}$ & 888 & 888 & 888 & 888 \\
\hline $\mathrm{R}^{2}$ ajustado & 0,971 & 0,811 & 0,901 & 0,963 \\
\hline Estatística F & $9.825,23 * * *$ & $1.267,050^{* * *}$ & $2.688,530^{* * *}$ & $7.670,700^{* * *}$ \\
\hline \multirow[t]{2}{*}{ Teste de Chow } & $47,840 * * *$ & 0,310 & $57,070 * * *$ & $12,630 * * *$ \\
\hline & $\begin{array}{c}\text { Outras Receitas } \\
\text { Operacionais }\end{array}$ & $\begin{array}{c}\text { Outras Despesas } \\
\text { Operacionais }\end{array}$ & $\begin{array}{c}\text { Receita } \\
\text { Financeira }\end{array}$ & $\begin{array}{c}\text { Despesa } \\
\text { Financeira }\end{array}$ \\
\hline $\mathrm{X}_{\mathrm{t}}$ & $0,426 * * *$ & $0,346^{* * *}$ & $0,748^{* * *}$ & $0,752 * * *$ \\
\hline SUV & $-0,033$ & $-0,004$ & 0,017 & 0,025 \\
\hline $\mathrm{X}_{\mathrm{t} . \mathrm{SUV}}$ & $0,107^{*}$ & $0,172 * * *$ & 0,105 & $0,157^{*}$ \\
\hline Interseção & 0,000 & $-0,035^{* * *}$ & $-0,040$ & $-0,037^{*}$ \\
\hline $\mathrm{N}$ & 888 & 888 & 888 & 888 \\
\hline $\mathrm{R}^{2}$ ajustado & 0,223 & 0,295 & 0,734 & 0,761 \\
\hline Estatística F & $85,900 * * *$ & $124,560 * * *$ & $817,110^{* * *}$ & $941,730 * * *$ \\
\hline Teste de Chow & 1,76 & $3,390 * *$ & 0,37 & 1,87 \\
\hline
\end{tabular}

***, significante a $1 \% ; * *$, significante a $5 \%$; , significante a $10 \%$

Em1 é igual a divisão do desvio padrão do lucro operacional e desvio padrão do fluxo de caixa operacional, em que os menores valores representam empresas que suavizam mais seus resultados para o período de 2010-2015 (LEUZ; NANDA; WYSOCKI, 2003). O cálculo da persistência segue o modelo adaptado de Dechow, Ge e Schrand (2010), sendo: $X_{t+1}=\alpha+\beta_{1} X_{t}+\beta_{2} S U V+\beta_{3} X_{t} \cdot S U V+\varepsilon$. Em que: $X$ representa as contas de resultado como receita líquida, $\mathrm{CPV}$, despesa administrativa, despesa de venda, outras receitas/despesas operacionais, receita financeira e despesa financeira; SUV é uma dummy para suavização, igual a 1 para empresas que mais suavizam o lucro líquido de acordo com o modelo de suavização EM1 e, zero para empresas que menos suavizam o lucro líquido; $\varepsilon$ é o erro da regressão e t é o ano. $\mathrm{O}$ N representa o número de observações.

De acordo com a Tabela 5, as contas de resultado que apresentam valores do beta 3 maiores que zero são receita líquida, despesa administrativa, despesa de venda e outras despesas operacionais, sendo 0,$153 ; 0314 ; 0,185$ e 0,172 , respectivamente, e significantes a $1 \%$. Além disso, para essas contas de resultado, é possível rejeitar a hipótese de estabilidade dos parâmetros, o que se observa através dos valores do teste de Chow, que são 47,840; 57,070 e 12,630 significantes a 1\% para as mesmas contas de resultado, nessa ordem. Já para conta de resultado, outras despesas operacionais, também é possível rejeitar a hipótese de estabilidade dos parâmetros, porém com significância estatística de 5\%, uma vez que o valor do teste de Chow para essa conta de resultado é 3,390. 
Esses resultados apontam que as empresas que mais suavizam o lucro líquido apresentam persistência das contas de resultado diferentes das empresas que menos suavizam o lucro líquido. E, ainda, as empresas que mais suavizam o lucro líquido apresentam contas de resultado como receita líquida, despesa administrativa, despesa de vendas e outras despesas operacionais mais persistentes que as empresas que menos suavizam o lucro líquido.

Nesse sentido, para essas contas de resultado não é possível rejeitar a primeira hipótese desta pesquisa que afirma que empresas que mais suavizam o lucro líquido apresentam contas de resultado mais persistentes. Uma possível interpretação para esses resultados é que o investidor que projetar fluxo de caixa futuro baseado nessas contas de resultado poderá não ter acurácia na projeção quando projetar esses fluxos para empresas que mais suavizam o lucro líquido. Isto porque é preciso levar em consideração que empresas que mais suavizam o lucro líquido podem gerenciar essas contas de maneira oportunista, o que diminui a capacidade de tais contas de revelar informação futura da empresa, impactando negativamente na capacidade do investidor em fazer um bom investimento e, ainda, atribuir valor às empresas que analisar.

Uma vez que empresas que mais suavizam o lucro líquido apresentam maior quantidade de accruals nesse lucro (DECHOW, 1994; LEUZ; NANDA; WYSOCKI, 2003; TUCKER; ZAROWIN, 2006), a quantidade de accruals discricionários também tende a aumentar, o que traz maior subjetividade na mensuração desse lucro e, consequentemente, maior oportunismo do gestor (XIE, 2001). Assim, é possível que empresas que suavizam o lucro líquido tenham contas de resultado mais subjetivas devido à maior presença de accruals discricionários, que podem não virar caixa em períodos futuros, prejudicando o investidor que projeta fluxo de caixa através de tais contas de resultado em empresas que mais suavizam o lucro líquido.

De maneira a confirmar os resultados da Tabela 5 e torná-los mais robustos, o apêndice A traz duas tabelas que separam as empresas que mais suavizam e menos suavizam o lucro líquido com os modelos de suavização EM1 e TZ. Ambos os resultados apontam para a não rejeição da primeira hipótese, o que sugere que a persistência das contas de resultado aumenta quando o lucro líquido é mais suavizado. Entretanto, cabe reforçar que não é possível afirmar que a qualidade da informação contábil aumenta, uma vez que os modelos de suavização utilizados não são precisos em identificar suavização artificial, cuja intenção do gestor é oportunista. 


\subsection{Persistência das contas de resultado nas empresas que mais suavizam o lucro líquido com maior e menor quantidade de accruals discricionários}

Para separar as empresas que mais suavizam o lucro líquido, utilizou-se o modelo de suavização do lucro líquido 1 (EM1), além disso, foram consideradas empresas que mais suavizam o lucro as que possuem menores valores de EM1 utilizando a mediana como referência. Após essa separação, foram calculados os valores de TZ, obtidos através do modelo de suavização do lucro líquido Tucker-Zarowin (TZ) (TUCKER; ZAROWIN, 2006), nesse caso, considerou-se como empresas que mais suavizam o lucro líquido com maior quantidade de accruals discricionários as empresas pertencentes ao primeiro quartil dessa amostra, cujo os valores de TZ são os menores calculados. Por outro lado, para as empresas que mais suavizam o lucro líquido com menor quantidade de accruals discricionários, considerou-se as empresas do $4^{\circ}$ quartil dessa amostra e que possuem os maiores valores de TZ.

A Tabela 6 apresenta os valores da persistência das contas de resultado utilizando o modelo de persistência adaptado de Dechow, Ge e Schrand (2010) para o período de 2010 a 2015, após separar as empresas que mais suavizam o lucro líquido com maior e menor quantidade de accruals discricionários.

Tabela 6 - Persistência das contas de resultado das empresas que mais suavizam o lucro com maior e menor quantidade de accruals discricionários

(continua)

$$
X_{t+1}=\alpha+\beta_{1} X_{t}+\beta_{2} S U V+\beta_{3} X_{t} \cdot S U V+\varepsilon
$$

\begin{tabular}{lcccc}
\hline & Receita Líquida & CPV & $\begin{array}{c}\text { Despesa } \\
\text { Administrativa }\end{array}$ & $\begin{array}{c}\text { Despesa de } \\
\text { Venda }\end{array}$ \\
\hline $\mathrm{X}_{\mathrm{t}}$ & $0,937 * * *$ & $1,032^{* * *}$ & $0,919 * * *$ & $0,867 * * *$ \\
$\mathrm{SUV}$ & $0,028^{* * *}$ & 0,055 & $0,025^{*}$ & $0,053^{*}$ \\
$\mathrm{X}_{\mathrm{t} . \mathrm{SUV}}$ & $\mathbf{0 , 0 8 5 * *}$ & 0,160 & 0,044 & $\mathbf{0 , 1 4 6 * * *}$ \\
Interseção & $-0,015^{*}$ & 0,010 & $-0,016$ & $-0,032$ \\
$\mathrm{~N}$ & 456 & 456 & 456 & 456 \\
$\mathrm{R}^{2}$ ajustado & 0,983 & 0,796 & 0,811 & 0,958 \\
Estatística F & $8.768 .961 * * *$ & $593.613 * * *$ & $653.757 * * *$ & $3.483 .621 * * *$ \\
Teste de Chow & $\mathbf{6 , 8 5 0 * * *}$ & 0,740 & $2,810 *$ & $\mathbf{1 9 , 1 5 0 * * *}$
\end{tabular}


Tabela 6 - Persistência das contas de resultado das empresas que mais suavizam o lucro com maior e menor quantidade de accruals discricionários

\begin{tabular}{lcccc}
\hline & $\begin{array}{c}\text { Outras Receitas } \\
\text { Operacionais }\end{array}$ & $\begin{array}{c}\text { Outras Despesas } \\
\text { Operacionais }\end{array}$ & $\begin{array}{c}\text { Receita } \\
\text { Financeira }\end{array}$ & $\begin{array}{c}\text { Despesa } \\
\text { Financeira }\end{array}$ \\
\hline $\mathrm{X}_{\mathrm{t}}$ & 0,005 & $0,259^{* * *}$ & $0,811^{* * *}$ & $0,767^{* * * *}$ \\
SUV & $0,137^{*}$ & $0,042^{*}$ & $0,058^{*}$ & $0,057^{* *}$ \\
$\mathrm{X}_{\mathrm{t}} \mathrm{SUV}$ & $\mathbf{0 , 6 6 4 * * *}$ & $\mathbf{0 , 4 4 0 * * *}$ & 0,077 & $\mathbf{0 , 1 5 0}$ \\
Interseção & $-0,132^{* * *}$ & $-0,057^{* * *}$ & $-0,035$ & $-0,043^{* *}$ \\
$\mathrm{~N}$ & 456 & 456 & 456 & 456 \\
$\mathrm{R}^{2}$ ajustado & 0,250 & 0,278 & 0,627 & 0,786 \\
Estatística F & $51.627^{* * *}$ & $59.410^{* * *}$ & $255.426^{* * *}$ & $559.668^{* * *}$ \\
Teste de Chow & $\mathbf{4 0 , 8 0 0 * * *}$ & $\mathbf{1 6 , 8 5 0 * * *}$ & $2,840^{*}$ & $\mathbf{5 , 2 2 0} * * *$ \\
\hline
\end{tabular}

***, significante a $1 \%$;**, significante a $5 \%$; , significante a $10 \%$

Em1 é igual a divisão do desvio padrão do lucro operacional e desvio padrão do fluxo de caixa operacional, em que os menores valores representam empresas que suavizam mais seus resultados para o período de 2010-2015 (LEUZ; NANDA; WYSOCKI, 2003). TZ é igual a correlação da variação da proxy para accruals discricionários e variação do lucro pré-discricionário, em que os menores valores representam as empresas que mais suavizam o lucro (LEUZ; NANDA; WYSOCKI, 2003; TUCKER; ZAROWIN, 2006). O cálculo da persistência segue o modelo adaptado de Dechow, Ge e Schrand (2010), sendo: $X_{t+1}=\alpha+\beta_{1} X_{t}+\beta_{2} S U V+\beta_{3} X_{t} \cdot S U V+\varepsilon$. Em que: X representa as contas de resultado como receita líquida, CPV, despesa administrativa, despesa de venda, outras receitas/despesas operacionais, receita financeira e despesa financeira; SUV é uma dummy para suavização, igual a 1 para empresas que mais suavizam o lucro líquido com maior quantidade de accruals discricionários de acordo com os modelos de suavização EM1-TZ e, zero para empresas que mais suavizam o lucro líquido com menor quantidade desses accruals; $\varepsilon$ é o erro da regressão e t é o ano. O N representa o número de observações.

Considerando-se a Tabela 6, observa-se que, para as contas de resultado, receita líquida, despesa de venda, outras receitas operacionais, outras despesas operacionais e despesa financeira, o beta 3 apresenta valores de 0,$085 ; 0,146 ; 0,664 ; 0,440$ e 0,150 , respectivamente, e com significância estatística entre $1 \%$ a $10 \%$ para as respectivas contas de resultado. Além disso, o teste de Chow que testa a estabilidade estrutural mostra que tais contas possuem valores superiores quando comparados ao valor do F crítico a $1 \%$ e, portanto, permite rejeitar a hipótese de estabilidade estrutural. Assim, não é possível rejeitar a segunda hipótese dessa pesquisa que afirma que as empresas que mais suavizam o lucro líquido com maior quantidade de accruals discricionários possuem contas de resultado mais persistentes quando comparadas com as contas das empresas que mais suavizam o lucro líquido com menor quantidade desses accruals.

Os resultados, nesse contexto, sugerem que o aumento da persistência está ligado à maior quantidade de accruals discricionários existentes na composição do lucro devido à suavização deste pelos gestores. Apesar de não ser possível identificar com precisão a suavização artificial do lucro, é possível que parte desse lucro seja suavizado artificialmente, pois quanto maior a quantidade de accruals discricionários na composição do lucro líquido, maior a subjetividade 
e a possibilidade de oportunismo pelo gestor (XIE, 2001). Nesse sentido, é possível que uma parte do aumento da persistência nas contas de resultado das empresas que mais suavizam o lucro líquido com maior quantidade de accruals discricionários seja caracterizada como persistência artificial devido à relação direta existente entre as duas proxies de qualidade da informação contábil.

Cabe ao investidor, no entanto, considerar o efeito da suavização do lucro líquido sobre a persistência das contas de resultado quando este decidir sobre determinado investimento utilizando as contas de resultado para projetar desempenho financeiro futuro da empresa analisada. Caso essa empresa seja uma das que mais suavizam com maior quantidade de accruals discricionários, pode ser possível que o gestor esteja suavizando artificialmente tais contas de resultado com o objetivo de manipular essas contas para que fiquem mais persistentes, o que faz a persistência ser caracterizada como artificial. Assim, os resultados projetados pelo investidor sobre o desempenho financeiro dessa empresa poderão ser enganosos, levando esse investidor à decisão de investimento insatisfatório.

Com a intenção de aumentar a robustez dos resultados da Tabela 6, o apêndice B traz uma segunda tabela que separa as empresas que mais suavizam o lucro líquido com maior e menor quantidade de accruals discricionários utilizando o modelo de suavização EM2 seguido pelo modelo de suavização TZ.

De maneira resumida, ao analisar os resultados da tabela 6 em conjunto com os resultados da Tabela B 1 que está no apêndice B, para ambas as tabelas, os resultados mostram que empresas que mais suavizam o lucro líquido com maior quantidade de accruals discricionários possuem contas de resultado mais persistentes. Cabe esclarecer que tais contas podem estar sujeitas à subjetividade, uma vez que o gestor possui certa discrição ao agrupar nessas contas de resultado outras contas com características semelhantes, através da contabilização pelo método da função da despesa, como considera o CPC 26 (R1). Assim, apesar dos resultados não permitirem afirmar que a suavização do lucro pelo gestor seja artificial, ainda assim, cabe considerar que pode existir o oportunismo na ação do gestor ao suavizar o lucro líquido e, nesse caso, a persistência dessas contas de resultado também é caracterizada como artificial, o que não permite afirmar que a suavização do lucro aumenta a qualidade da informação contábil. 


\section{CONSIDERAÇÕES FINAIS}

Segundo Barton, Hansen e Pownall (2010), as contas presentes nas linhas do meio da DRE são mais relevantes para o investidor no processo de avaliação patrimonial porque capturam, de forma rápida e direta, a informação sobre fluxo de caixa da empresa. Entretanto, é possível que essas contas de resultado estejam sujeitas à discrição do gestor. De acordo com Subramanyam (1996), Tucker e Zarowin (2006) a suavização do lucro líquido aumenta a persistência desse lucro e, consequentemente, aumenta a capacidade do investidor em projetar fluxo de caixa futuro de uma empresa porque no lucro existem accruals capazes de aumentar o poder de explicação do fluxo de caixa futuro da empresa (DECHOW, 1994).

Por outro lado, Sloan (1996) e Richardson et al. (2005) afirmam que a causa provável da má atribuição de preço às ações pelos investidores no mercado são os accruals que são menos persistentes que fluxo de caixa e estão presentes no lucro líquido, pois estes podem não ser confiáveis, o que torna a projeção de fluxo de caixa enviesada. Ademais, conforme Barth, Landsman e Lang (2008), a suavização do lucro através dos accruals discricionários, apesar de aumentar a capacidade de previsão de fluxo de caixa pelo investidor, aumenta a discrição do gestor sobre esse lucro, podendo com isso aumentar o oportunismo deste ao contabilizar o lucro líquido, o que impacta negativamente sobre a qualidade da informação contábil.

Diante das conclusões divergentes envolvendo suavização e persistência do lucro líquido e, também, qualidade da informação contábil, cabe a seguinte pergunta: Como o objetivo de suavização do lucro líquido pode alterar a persistência das contas de resultado?

Os resultados mostram que as empresas que mais suavizam o lucro líquido, de acordo com o modelo de suavização EM1, apresentam contas de resultados operacionais mais persistentes que empresas que menos suavizam esse lucro. Contudo, devido a esses modelos de suavização considerar os accruals totais, não os separando entre accruals discricionários e não discricionários, não é possível dizer que a persistência aumenta exclusivamente com as ações discricionárias do gestor. Mas, também é possível dizer que essas empresas apresentam maior quantidade de accruals discricionários distribuídos nas contas de resultado devido ao aumento dos accruals através da suavização do lucro, o que pode sujeitar essas contas ao oportunismo do gestor, uma vez que a subjetividade aumenta com a presença de accruals discricionários (XIE, 2001). Nesse caso, o aumento da persistência nas contas de resultado devido à maior 
suavização do lucro líquido pelo gestor, pode tanto diminuir a qualidade da informação contábil como, também, aumentar essa qualidade.

Ao separar as empresas que mais suavizam o lucro líquido com maior e menor quantidade de accruals discricionários de acordo com o modelo de suavização EM1 e TZ, percebe-se que tanto as contas de resultado ligadas à operação quando às ligadas ao resultado financeiro apresentam maior persistência quando a empresa suaviza mais seu lucro líquido com maior quantidade de accruals discricionários. Os resultados dessa separação sugerem que é possível que o gestor esteja suavizando as contas de resultado com intenção de tornar explícita uma informação privada, mas também podem sugerir que a suavização tem como objetivo apenas manipulação artificial. Assim, o aumento da persistência das contas de resultado das empresas que mais suavizam o lucro com maior quantidade de accruals discricionários pode ser artificial, tornando a persistência uma proxy que deve ser analisada com cautela na discussão sobre qualidade da informação contábil.

Esta pesquisa contribui com a literatura sobre suavização e persistência do lucro líquido, buscando explicar a suavização desse lucro por meio da persistência das contas de resultado. Nesse sentido, em um ambiente de intensa manipulação de accruals com o objetivo de suavizar o lucro líquido, o aumento da persistência das contas de resultado pode ter natureza artificial. Com isso, o investidor precisa ter certo cuidado ao projetar fluxo de caixa baseado em contas de resultado, pois é possível que tal manipulação seja oportunista, o que deixa as contas de resultado com pouco poder de explicação sobre o fluxo de caixa futuro da empresa. Além disso, o investidor pode ser levado ao erro na precificação dos ativos dessas empresas por não ser capaz de calcular corretamente o verdadeiro desempenho financeiro destas.

Sugere-se que novas pesquisas sejam realizadas utilizando outros modelos de suavização do lucro líquido e outras contas de resultado para verificar se a suavização é capaz de alterar a persistência dessas contas e qual a consequência desse gerenciamento nas decisões de investimento dos investidores. 


\section{REFERENCIAS}

AHMED, Anwer S.; NEEL, Michael; WANG, Dechun. Does mandatory adoption of IFRS improve accounting quality? Preliminary evidence. Contemporary Accounting Research, v. 30, n. 4, p. 1344-1372, 2013.

ARTIKIS, Panagiotis G.; PAPANASTASOPOULOS, Georgios A. Implications of the cash component of earnings for earnings persistence and stock returns. The British Accounting Review, v. 48, n. 2, p. 117-133, 2016.

BARTH, Mary E.; CRAM, Donald P.; NELSON, Karen K. Accruals and the prediction of future cash flows. The accounting review, v. 76, n. 1, p. 27-58, 2001.

BARTH, Mary E.; LANDSMAN, Wayne R.; LANG, Mark H. International accounting standards and accounting quality. Journal of accounting research, v. 46, n. 3, p. 467-498, 2008 .

BARTON, Jan; HANSEN, Thomas Bowe; POWNALL, Grace. Which performance measures do investors around the world value the most-And why?. The Accounting Review, v. 85, n. 3, p. 753-789, 2010.

BEIDLEMAN, Carl R. Income smoothing: The role of management. Accounting review, p. 653-667, 1973.

COLLINS, Daniel W.; KOTHARI, S. P. An analysis of intertemporal and cross-sectional determinants of earnings response coefficients. Journal of accounting and economics, v. 11, n. 2, p. 143-181, 1989.

COMITÊ, DE PRONUNCIAMENTOS CONTÁBEIS. Pronunciamento Técnico CPC 26 (R1): apresentação das demonstrações contábeis. Brasília, DF, v. 2, 2011.

DECHOW, Patricia; GE, Weili; SCHRAND, Catherine. Understanding earnings quality: A review of the proxies, their determinants and their consequences. Journal of accounting and economics, v. 50, n. 2, p. 344-401, 2010.

DECHOW, Patricia M. Accounting earnings and cash flows as measures of firm performance: The role of accounting accruals. Journal of accounting and economics, v. 18, n. 1, p. 3-42, 1994.

DECHOW, Patricia M.; DICHEV, Ilia D. The quality of accruals and earnings: The role of accrual estimation errors. The accounting review, v. 77, n. s-1, p. 35-59, 2002.

DECHOW, Patricia M.; KOTHARI, Sagar P.; WATTS, Ross L. The relation between earnings and cash flows. Journal of accounting and economics, v. 25, n. 2, p. 133-168, 1998.

DECHOW, Patricia M.; RICHARDSON, Scott A.; SLOAN, Richard G. The persistence and pricing of the cash component of earnings. Journal of Accounting Research, v. 46, n. 3, p. 537-566, 2008. 
DECHOW, Patricia M.; SLOAN, Richard G.; SWEENEY, Amy P. Detecting earnings management. Accounting review, p. 193-225, 1995.

DEFOND, Mark L.; PARK, Chul W. Smoothing income in anticipation of future earnings. Journal of accounting and economics, v. 23, n. 2, p. 115-139, 1997.

DICHEV, Ilia D. et al. Earnings quality: Evidence from the field. Journal of Accounting and Economics, v. 56, n. 2, p. 1-33, 2013.

DOU, Yiwei; HOPE, Ole-Kristian; THOMAS, Wayne B. Relationship-specificity, contract enforceability, and income smoothing. The accounting review, v. 88, n. 5, p. 1629-1656, 2013.

ECKEL, Norm. The income smoothing hypothesis revisited. Abacus, v. 17, n. 1, p. 28-40, 1981.

ENOMOTO, Masahiro; KIMURA, Fumihiko; YAMAGUCHI, Tomoyasu. Accrual-based and real earnings management: An international comparison for investor protection. Journal of Contemporary Accounting \& Economics, v. 11, n. 3, p. 183-198, 2015.

EWERT, Ralf; WAGENHOFER, Alfred. Economic Relations Among Earnings Quality Measures. Abacus, v. 51, n. 3, p. 311-355, 2015.

FAIRFIELD, Patricia M.; WHISENANT, J. Scott; YOHN, Teri Lombardi. Accrued earnings and growth: Implications for future profitability and market mispricing. The accounting review, v. 78, n. 1, p. 353-371, 2003.

FIELDS, Thomas D.; LYS, Thomas Z.; VINCENT, Linda. Empirical research on accounting choice. Journal of accounting and economics, v. 31, n. 1, p. 255-307, 2001.FUDENBERG, Drew; TIROLE, Jean. A theory of income and dividend smoothing based on incumbency rents. Journal of political economy, p. 75-93, 1995.

GAO, Lei; ZHANG, Joseph H. Firms' earnings smoothing, corporate social responsibility, and valuation. Journal of Corporate Finance, v. 32, p. 108-127, 2015.

GORDON, Myron J. Postulates, principles and research in accounting. Accounting review, p. 251-263, 1964.

GOVENDIR, Brett; WELLS, Peter. The influence of the accruals generating process on earnings persistence. Australian journal of management, v.39, n.4, p. 593-614, 2014.

GRAHAM, John R.; HARVEY, Campbell R.; RAJGOPAL, Shiva. The economic implications of corporate financial reporting. Journal of accounting and economics, v. 40, n. 1, p. 3-73, 2005.

GUJARATI, Damodar N.; PORTER, Dawn C. Econometria Básica-5. AMGH Editora, 2011.

HEALY, Paul M. The effect of bonus schemes on accounting decisions. Journal of accounting and economics, v. 7, n. 1, p. 85-107, 1985. 
HEALY, Paul M.; WAHLEN, James M. A review of the earnings management literature and its implications for standard setting. Accounting horizons, v. 13, n. 4, p. 365-383, 1999.

HUI, Kai Wai; NELSON, Karen K.; YEUNG, P. Eric. On the persistence and pricing of industry-wide and firm-specific earnings, cash flows, and accruals. Journal of Accounting and Economics, v. 61, n. 1, p. 185-202, 2016.

KHALIL, Mohamed; SIMON, Jon. Efficient contracting, earnings smoothing and managerial accounting discretion. Journal of Applied Accounting Research, v. 15, n. 1, p. 100-123, 2014.

KIRSCHENHEITER, Michael; MELUMAD, Nahum D. Can "Big Bath" and Earnings Smoothing Co-exist as Equilibrium Financial Reporting Strategies?. Journal of Accounting Research, v. 40, n. 3, p. 761-796, 2002.

KOTHARI, Sagar P.; LEONE, Andrew J.; WASLEY, Charles E. Performance matched discretionary accrual measures. Journal of accounting and economics, v. 39, n. 1, p. 163-197, 2005.

LAMBERT, Richard A. Income smoothing as rational equilibrium behavior. Accounting review, p. 604-618, 1984.

LEUZ, Christian; NANDA, Dhananjay; WYSOCKI, Peter D. Earnings management and investor protection: an international comparison. Journal of financial economics, v. 69, n. 3 , p. 505-527, 2003.

MYERS, James N.; MYERS, Linda A.; SKINNER, Douglas J. Earnings momentum and earnings management. Journal of Accounting, Auditing \& Finance, v. 22, n. 2, p. 249-284, 2007.

PENMAN, Stephen H.; SOUGIANNIS, Theodore. A Comparison of Dividend, Cash Flow, and Earnings Approaches to Equity Valuation*. Contemporary Accounting Research, v. 15, n. 3, p. 343-383, 1998.

PEROTTI, Pietro; WAGENHOFER, Alfred. Earnings quality measures and excess returns. Journal of business finance \& accounting, v. 41, n. 5-6, p. 545-571, 2014.

PINCUS, Morton; RAJGOPAL, Shivaram; VENKATACHALAM, Mohan. The accrual anomaly: International evidence. The Accounting Review, v. 82, n. 1, p. 169-203, 2007.

RICHARDSON, Scott A. et al. Accrual reliability, earnings persistence and stock prices. Journal of accounting and economics, v. 39, n. 3, p. 437-485, 2005.

RONEN, Joshua; SADAN, S. Smoothing Income Numbers: Objectives, Means And Implications (Addison-Wesley Paperback Series In Accounting) Author: Josh. 1981.

SALEWSKI, Marcus; ZÜLCH, Henning. Discretion in the accounting for defined benefit obligations-an empirical analysis of German IFRS statements. Journal of Pension Economics and Finance, v. 14, n. 03, p. 266-292, 2015. 
SANKAR, Mandira Roy; SUBRAMANYAM, K. R. Reporting discretion and private information communication through earnings. Journal of Accounting Research, v. 39, n. 2, p. 365-386, 2001.

SCOTT, William Robert. Financial accounting theory. Upper Saddle River, NJ: Prentice Hall, 2009.

SLOAN, R. Do stock prices fully reflect information in accruals and cash flows about future earnings? (Digest Summary). Accounting review, v. 71, n. 3, p. 289-315, 1996.

SUBRAMANYAM, K. R. The pricing of discretionary accruals. Journal of accounting and economics, v. 22, n. 1, p. 249-281, 1996.

TRUEMAN, Brett; TITMAN, Sheridan. An explanation for accounting income smoothing. Journal of accounting research, p. 127-139, 1988.

TUCKER, Jennifer W.; ZAROWIN, Paul A. Does income smoothing improve earnings informativeness?.The Accounting Review, v. 81, n. 1, p. 251-270, 2006.

XIE, Hong. The mispricing of abnormal accruals. The accounting review, v. 76, n. 3, p. 357$373,2001$. 


\section{APÊNDICE}

\section{APÊNDICE A - Análise complementar sobre a persistência das contas de resultado das empresas que mais e menos suavizam o lucro líquido}

Com o objetivo de confirmar os resultados obtidos com a Tabela 5, as Tabela A 1 e Tabela A 2 são apresentadas, separando as empresas que mais e menos suavizam o lucro líquido de acordo com outros dois modelos de suavização propostos nesta pesquisa, quais sejam os modelos de suavização do lucro líquido EM2 e TZ.

A Tabela A 1 apresenta os resultados da regressão segundo o modelo adaptado de Dechow, Ge e Schrand (2010) sobre a persistência das contas de resultado durante os anos de 2010 a 2015.

Cada coluna dessa tabela representa uma regressão linear múltipla em cross-section.

Tabela A 1 - Persistência das contas de resultado partindo do modelo de suavização EM2

\begin{tabular}{|c|c|c|c|c|}
\hline & Receita Líquida & CPV & $\begin{array}{c}\text { Despesa } \\
\text { Administrativa }\end{array}$ & $\begin{array}{c}\text { Despesa de } \\
\text { Venda }\end{array}$ \\
\hline $\mathrm{X}_{\mathrm{t}}$ & $0,958 * * *$ & $1,234 * * *$ & $0,633 * * *$ & $0,800 * * *$ \\
\hline SUV & $0,022 * * *$ & 0,009 & $0,062 * * *$ & $0,061 * * *$ \\
\hline $\mathrm{X}_{\mathrm{t} . \mathrm{SUV}}$ & $\mathbf{0 , 1 3 0} * * *$ & $0,119^{*}$ & $\mathbf{0 , 3 4 4} * * *$ & $0,225 * * *$ \\
\hline Interseção & $-0,0109 *$ & $0,053^{* *}$ & $-0,052 * * *$ & $-0,045^{* * *}$ \\
\hline $\mathrm{N}$ & 888 & 888 & 888 & 888 \\
\hline $\mathrm{R}^{2}$ ajustado & 0,971 & 0,753 & 0,882 & 0,959 \\
\hline Estatística F & $9.743,010^{* * *}$ & $900,300 * * *$ & $2.207,500^{* * *}$ & $6.937,960 * * *$ \\
\hline \multirow[t]{2}{*}{ Teste de Chow } & $55,480 * * *$ & 1,660 & $76,690 * * *$ & $8,050 * * *$ \\
\hline & $\begin{array}{c}\text { Outras Receitas } \\
\text { Operacionais }\end{array}$ & $\begin{array}{c}\text { Outras Despesas } \\
\text { Operacionais }\end{array}$ & $\begin{array}{c}\text { Receita } \\
\text { Financeira }\end{array}$ & $\begin{array}{c}\text { Despesa } \\
\text { Financeira }\end{array}$ \\
\hline$X_{t}$ & $0,412 * * *$ & $0,651 * * *$ & $0,813 * * *$ & $0,861 * * *$ \\
\hline SUV & 0,021 & $-0,017$ & 0,022 & 0,015 \\
\hline $\mathrm{X}_{\mathrm{t}} \mathrm{SUVV}$ & $0,248 * * *$ & $-0,032$ & $-0,143 *$ & 0,078 \\
\hline Interseção & $-0,030$ & $-0,008$ & $-0,012$ & $-0,008$ \\
\hline $\mathrm{N}$ & 888 & 888 & 888 & 888 \\
\hline $\mathrm{R}^{2}$ ajustado & 0,333 & 0,590 & 0,685 & 0,781 \\
\hline Estatística F & $148,250 * * *$ & $424,320 * * *$ & $643,060 * * *$ & $1.053,150^{* * *}$ \\
\hline Teste de Chow & $11,790 * * *$ & 0,25 & 1,99 & 0,53 \\
\hline
\end{tabular}

***, significante a $1 \% ; * *$, significante a $5 \% ; *$, significante a $10 \%$ 
Em2 é igual a correlação da variação de accruals totais e variação de fluxo de caixa das operações, em que os menores valores representam as empresas que mais suavizam o lucro líquido para o período de 2010-2015 (LEUZ; NANDA; WYSOCKI, 2003; TUCKER; ZAROWIN, 2006). O cálculo da persistência segue o modelo adaptado de Dechow, Ge e Schrand (2010), sendo: $X_{t+1}=\alpha+\beta_{1} X_{t}+\beta_{2} S U V+\beta_{3} X_{t}$.SUV $+\varepsilon$. Em que: X representa as contas de resultado como receita líquida, CPV, despesa administrativa, despesa de venda, outras receitas/despesas operacionais, receita financeira e despesa financeira; SUV é uma dummy para suavização, igual a 1 para empresas que mais suavizam o lucro líquido de acordo com o modelo de suavização EM2 e, zero para empresas que menos suavizam o lucro líquido; $\varepsilon$ é o erro da regressão e t é o ano. $\mathrm{O} \mathrm{N}$ representa o número de observações.

De acordo com a Tabela A 1, para as contas de resultado, receita líquida, despesa administrativa, despesa de venda e outras receitas operacionais, o que se verifica é que, para as empresas que mais suavizam o lucro líquido, a persistência dessas contas é maior. Nesse sentido, para as empresas que mais suavizam o lucro líquido, a persistência dessas contas de resultado é, nessa ordem, $13 \%, 34,4 \%, 22,5 \%$ e $24,8 \%$, significantes a $1 \%$, maiores que a persistência das mesmas contas de resultado das empresas que menos suavizam o lucro líquido.

O teste de Chow para essas contas de resultado é que permite afirmar que tais contas são mais persistentes para empresas que mais suavizam o lucro líquido em comparação com as que menos suavizam esse lucro porque esse teste permite rejeitar a hipótese de estabilidade dos parâmetros. Portanto, a persistência das contas de resultado, receita líquida, despesa administrativa, despesa de vendas e outras receitas operacionais é maior para empresas que mais suavizam o lucro líquido de acordo com o modelo de suavização EM2. Assim, para essas contas de resultado, não é possível rejeitar a hipótese de que as contas de resultado das empresas que mais suavizam o lucro líquido são mais persistentes que as contas de resultado das empresas que menos suavizam esse lucro.

Ao analisar as Tabela 5 e Tabela A 1 em conjunto, observa-se que, para empresas que mais suavizam o lucro líquido, a persistência das contas de resultado é maior para contas de natureza operacional. Apesar dos resultados dessas tabelas não permitirem a afirmação de que a suavização é no sentido de enganar o investidor, as empresas que mais suavizam o lucro líquido apresentam maior proporção de accruals nessas contas de resultado, o que pode aumentar a quantidade de accruals discricionários. Assim, é necessária a cautela do investidor ao analisar tais contas nessas empresas, pois a percepção de risco do investimento tende a diminuir e não é possível afirmar se a suavização dessas contas é artificial ou não (ECKEL, 1981; GRAHAM et al., 2005). 
A Tabela A 2 apresenta os resultados das regressões lineares adaptadas de Dechow, Ge e Schrand (2010) para as contas de resultado no período de 2010 a 2015 após classificar as empresas que mais suavizam e menos suavizam o lucro líquido de acordo com o modelo de suavização TZ. Essa tabela traz os resultados da persistência, $\mathrm{R}^{2}$ ajustado, estatística F e o teste de Chow de cada conta de resultado. Cada coluna dessa tabela representa uma regressão linear múltipla em cross-section.

Tabela A 2 - Persistência das contas de resultado partindo do modelo de suavização TZ

$$
X_{t+1}=\alpha+\beta_{1} X_{t}+\beta_{2} S U V+\beta_{3} X_{t} . S U V+\varepsilon
$$

\begin{tabular}{|c|c|c|c|c|}
\hline & Receita Líquida & CPV & $\begin{array}{c}\text { Despesa } \\
\text { Administrativa }\end{array}$ & $\begin{array}{c}\text { Despesa de } \\
\text { Vendas }\end{array}$ \\
\hline $\mathrm{X}_{\mathrm{t}}$ & $0,561 * * *$ & $1,028^{* * *}$ & $0,620 * * *$ & $0,790 * * *$ \\
\hline SUV & $0,109 * * *$ & 0,047 & $0,083 * * *$ & $0,070 * * *$ \\
\hline $\mathrm{X}_{\mathrm{t}} \mathrm{SUV}$ & $\mathbf{0 , 5 3 2 * * *}$ & 0,342 & $0,368 * * *$ & $0,227 * * *$ \\
\hline Interseção & $-0,100 * * *$ & 0,009 & $-0,069 * * *$ & $-0,050 * *$ \\
\hline $\mathrm{N}$ & 888 & 888 & 888 & 888 \\
\hline $\mathrm{R}^{2}$ ajustado & 0,975 & 0,746 & 0,888 & 0,947 \\
\hline Estatística F & $11.310,520^{* * *}$ & $870,320 * * *$ & $2.336,270^{* * *}$ & $5.251,070^{* * *}$ \\
\hline \multirow[t]{2}{*}{ Teste de Chow } & $90,230 * * *$ & 1,180 & $124,46^{* * * *}$ & $4,710 * * *$ \\
\hline & $\begin{array}{c}\text { Outras Receitas } \\
\text { Operacionais }\end{array}$ & $\begin{array}{c}\text { Outras Despesas } \\
\text { Operacionais }\end{array}$ & $\begin{array}{c}\text { Receita } \\
\text { Financeira }\end{array}$ & $\begin{array}{c}\text { Despesa } \\
\text { Financeira }\end{array}$ \\
\hline $\mathrm{X}_{\mathrm{t}}$ & $0,322 * * *$ & $0,323 * * *$ & $0,751 * * *$ & $0,749 * * *$ \\
\hline SUV & 0,048 & 0,014 & $0,073 *$ & $0,060^{*}$ \\
\hline $\mathrm{X}_{\mathrm{t} . \mathrm{SUV}}$ & $0,489 * * *$ & $0,205 * * *$ & $-0,056$ & $0,211 * * *$ \\
\hline Interseção & $-0,029$ & $-0,044 * * *$ & $-0,049 *$ & $-0,046 * *$ \\
\hline $\mathrm{N}$ & 888 & 888 & 888 & 888 \\
\hline $\mathrm{R}^{2}$ ajustado & 0,426 & 0,294 & 0,684 & 0,763 \\
\hline Estatística F & $219,960 * * *$ & $124,260 * * *$ & $639,520 * * *$ & $951,580 * * *$ \\
\hline Teste de Chow & $53,680 * * *$ & $8,020 * * *$ & 2,06 & $10,670 * * *$ \\
\hline
\end{tabular}

***, significante a $1 \% ; * *$, significante a $5 \% ; *$, significante a $10 \%$

TZ é igual a correlação da variação da proxy para accruals discricionários e variação do lucro pré-discricionário, em que os menores valores representam as empresas que mais suavizam seus resultados para o período de 20102015 (TUCKER; ZAROWIN, 2006). O cálculo da persistência segue o modelo adaptado de Dechow, Ge e Schrand (2010), sendo: $X_{t+1}=\alpha+\beta_{1} X_{t}+\beta_{2} S U V+\beta_{3} X_{t} . S U V+\varepsilon$. Em que: $X$ representa as contas de resultado como receita líquida, CPV, despesa administrativa, despesa de venda, outras receitas/despesas operacionais, receita financeira e despesa financeira; SUV é uma dummy para suavização, igual a 1 para empresas que mais suavizam o lucro líquido de acordo com o modelo de suavização $\mathrm{TZ}$ e, zero para empresas que menos suavizam o lucro líquido; $\varepsilon$ é o erro da regressão e t é o ano. $\mathrm{O} N$ representa o número de observações.

De acordo com a Tabela A 2, as contas de resultado, receita líquida, despesa administrativa, despesa de venda, outras receitas operacionais, outras despesas operacionais e despesa 
financeira apontam que a persistência destas é maior para empresas que mais suavizam o lucro líquido, pois o beta 3 para elas é positivo e estatisticamente significante a $1 \%$. Os resultados apontam que, para as empresas que mais suavizam o lucro líquido, a persistência das respectivas contas de resultado é $53,2 \% ; 36,8 \% ; 22,7 \% ; 48,9 \% ; 20,5 \%$ e $21,1 \%$ maior quando comparadas com a persistência das mesmas contas de resultado nas empresas que menos suavizam esse lucro.

Com os resultados do teste de Chow para essas contas de resultado citadas, é possível rejeitar a hipótese de estabilidade dos parâmetros, pois esse teste apresentou para cada uma das contas valores maiores que o valor crítico do teste a $1 \%$. Portanto, as empresas que mais suavizam o lucro líquido apresentam maior persistência em suas contas de resultado quando comparadas com as contas das empresas que menos suavizam esse lucro.

Neste sentido, para tais contas de resultado, não é possível rejeitar a primeira hipótese desta pesquisa que afirma que a persistência das contas de resultado é maior para empresas que mais suavizam o lucro líquido.

Considerando os resultados dessa tabela, conclui-se que, de forma geral, empresas que mais suavizam o lucro líquido possuem contas de resultado mais persistentes em comparação com empresas que menos suavizam esse lucro. Esses resultados sugerem que a suavização do lucro líquido pode ocorrer de modo natural, sem a influência da escolha do gestor, mas também pode ser por manipulação, onde está sujeita a discrição do gestor. Assim, a persistência das contas de resultado das empresas que mais suavizam o lucro pode ser caracterizada tanto como persistência natural das contas no processo de formação do lucro líquido, mas também pode ser uma persistência artificial, uma vez que não é conhecida a subjetividade dos accruals existentes nas contas. Portanto, não se pode afirmar que a persistência, nesse caso, aumenta a qualidade da informação contábil pois não se conhece o grau de oportunismo empregado pelo gestor na mensuração dessas contas.

\section{APÊNDICE B - Análise complementar sobre a persistência das contas de resultado das empresas que mais suavizam o lucro líquido com maior e menor quantidade de accruals discricionários}


Com o objetivo de verificar a consistência entre os modelos de suavização utilizados para separar as empresas que mais suavizam com maior e menor quantidade de accruals discricionários, foram realizados novos testes de persistência das contas de resultado após separar as empresas utilizando dois modelos de suavização de resultado, EM2 e TZ.

Para separar as empresas que mais suavizam o lucro líquido, utilizou-se o modelo de suavização do lucro líquido 2 (EM2) (LEUZ; NANDA; WYSOCKI, 2003), além disso, foram consideradas empresas que mais suavizam o lucro as que possuem os menores valores de EM2 utilizando a mediana como referência. Após essa separação, foram calculados os valores de TZ, obtidos através do modelo de suavização do lucro líquido Tucker-Zarowin (TZ) (TUCKER; ZAROWIN, 2006), nesse caso, considerou-se como empresas que mais suavizam o lucro líquido com maior quantidade de accruals discricionários as empresas pertencentes ao primeiro quartil dessa amostra, cujos valores de TZ são os menores calculados. Por outro lado, para as empresas que mais suavizam o lucro líquido com menor quantidade de accruals discricionários, considerou-se as empresas do $4^{\circ}$ quartil dessa amostra e que possuem os maiores valores de TZ.

Após separar as empresas através dos dois modelos de suavização acima citados, foi realizado o teste de persistência das contas de resultados com o propósito de verificar se a persistência das contas de resultado das empresas que mais suavizam o lucro com maior quantidade de accruals discricionários é maior em comparação com as contas de resultado das empresas que mais suavizam o lucro com menor quantidade de accruals discricionários.

A Tabela B 1 traz os resultados da persistência de cada conta de resultado analisada para o período de 2010 a 2015.

Tabela B 1 - Persistência das contas de resultado das empresas que mais suavizam com maior e menor quantidade de accruals discricionários (EM2-TZ)

\begin{tabular}{lcccc}
\hline \multicolumn{4}{c}{$\boldsymbol{X}_{\boldsymbol{t}+\mathbf{1}}=\boldsymbol{\alpha}+\boldsymbol{\beta}_{\mathbf{1}} \boldsymbol{X}_{\boldsymbol{t}}+\boldsymbol{\beta}_{\mathbf{2}} \boldsymbol{S U V}+\boldsymbol{\beta}_{3} \boldsymbol{X}_{\boldsymbol{t}} \cdot \boldsymbol{S U V}+\boldsymbol{\varepsilon}$} & (continua) \\
\hline & Receita Líquida & $\mathbf{C P V}$ & $\begin{array}{c}\text { Despesa } \\
\text { Administrativa }\end{array}$ & $\begin{array}{c}\text { Despesa de } \\
\text { Vendas }\end{array}$ \\
\hline $\mathrm{X}_{\mathrm{t}}$ & $1,000^{* * *}$ & $1,224^{* *}$ & $0,992^{* * *}$ & $0,807^{* * *}$ \\
SUV & 0,014 & $-0,001$ & 0,020 & 0,076 \\
$\mathrm{X}_{\mathrm{t} . S U V}$ & 0,104 & 0,167 & $-0,010$ & 0,232 \\
Interseção & 0 & 0,054 & $-0,001$ & $-0,045$
\end{tabular}


Tabela B 2 - Persistência das contas de resultado das empresas que mais suavizam com maior e menor quantidade de accruals discricionários (EM2-TZ)

\begin{tabular}{lcccc} 
& & & & (conclusão) \\
\hline $\mathrm{N}$ & 456 & 456 & 456 & 456 \\
$\mathrm{R}^{2}$ ajustado & 0,980 & 0,741 & 0,784 & 0,954 \\
Estatística $\mathrm{F}$ & $7.301 .582^{* * *}$ & $433.810^{* * *}$ & $550.356^{* * *}$ & $3.181 .762^{* * * *}$ \\
Teste de Chow & 1,190 & 0,200 & 1.470 & 0.960 \\
\hline & Outras Receitas & Outras Despesas & Receita & Despesa \\
& Operacionais & Operacionais & Financeira & Financeira \\
\hline $\mathrm{X}_{\mathrm{t}}$ & 0,025 & $0,159^{* *}$ & $0,827^{* * *}$ & $0,874^{* * *}$ \\
$\mathrm{SUV}$ & 0,127 & $0,064^{* * *}$ & 0,065 & 0,043 \\
$\mathrm{X}_{\mathrm{t} . S U V}$ & $\mathbf{0 , 6 3 5 * * *}$ & $\mathbf{0 , 5 1 7 * * *}$ & $-0,241$ & 0,031 \\
Interseção & $-0,122^{*}$ & $-0,082^{* * *}$ & $-0,029$ & $-0,026$ \\
$\mathrm{~N}$ & 456 & 456 & 456 & 456 \\
$\mathrm{R}^{2}$ ajustado & 0,236 & 0,247 & 0,288 & 0,750 \\
Estatística F & $47.832^{* * *}$ & $50.879 * * *$ & $62.428 * * *$ & $456.131^{* * *}$ \\
Teste de Chow & $\mathbf{3 3 , 6 5 0 * * *}$ & $\mathbf{2 2 , 8 2 0 * * *}$ & $3,360^{* *}$ & 1,880 \\
\hline
\end{tabular}

***, significante a $1 \% ; * *$, significante a $5 \% ; *$, significante a $10 \%$

Em2 é igual a correlação da variação de accruals totais e variação de fluxo de caixa das operações, em que os menores valores representam as empresas que mais suavizam seus resultados para o período de 2010-2015 (LEUZ; NANDA; WYSOCKI, 2003; TUCKER; ZAROWIN, 2006). TZ é igual a correlação da variação da proxy para accruals discricionários e variação do lucro pré-discricionário, em que os menores valores representam as empresas que mais suavizam seus resultados para o período de 2010-2015 (LEUZ; NANDA; WYSOCKI, 2003; TUCKER; ZAROWIN, 2006). O cálculo da persistência segue o modelo adaptado de Dechow, Ge e Schrand (2010), sendo: $X_{t+1}=\alpha+\beta_{1} X_{t}+\beta_{2} S U V+\beta_{3} X_{t}$.SUV $+\varepsilon$. Em que: $X$ representa as contas de resultado como receita líquida, $\mathrm{CPV}$, despesa administrativa, despesa de venda, outras receitas/despesas operacionais, receita financeira e despesa financeira; SUV é uma dummy para suavização, igual a 1 para empresas que mais suavizam o lucro líquido com maior quantidade de accruals discricionários de acordo com os modelos de suavização EM2-TZ e, zero para empresas que mais suavizam o lucro líquido com menor quantidade desses accruals; $\varepsilon$ é o erro da regressão e t é o ano. $\mathrm{O} \mathrm{N}$ representa o número de observações.

Ao analisar a Tabela B 1, nota-se que, para as empresas que mais suavizam o lucro líquido com maior quantidade de accruals discricionários, apenas as contas de resultado, outras receitas operacionais e outras despesas operacionais possuem maior persistência quando comparadas com as mesmas contas das empresas que mais suavizam o lucro com menor quantidade desses accruals. Além disso, observando os valores dos betas 3 de ambas as contas, é possível afirmar com um nível de segurança de $99 \%$ que, para as empresas que mais suavizam o lucro com maior quantidade de accruals discricionários, as persistências das contas de resultado, outras receitas operacionais e outras despesas operacionais são $6,35 \%$ e $5,17 \%$, respectivamente, maiores quando comparadas com as mesmas contas de resultado das empresas que mais suavizam o lucro líquido com menor quantidade desses accruals. 
$\mathrm{O}$ teste de Chow para essas duas contas de resultado possui valor $\mathrm{F}$ maior que o $\mathrm{F}$ crítico a $1 \%$, assim, é possível rejeitar a hipótese de que não há mudança estrutural, o que permite afirmar que a persistência para essas contas é diferente entre as empresas que mais suavizam o lucro com maior e menor quantidade de accruals discricionários.

Com os valores do beta 3 e teste de Chow para as contas de resultado, outras receitas operacionais e outras despesas operacionais, não se pode, portanto, rejeitar a segunda hipótese desta pesquisa que afirma que as empresas que mais suavizam o lucro líquido com maior quantidade de accruals discricionários possuem contas de resultado mais persistentes que as contas de resultado das empresas que mais suavizam o lucro com menor quantidade desses accruals.

Esses resultados sugerem que o gestor de uma empresa que mais suaviza o lucro com maior quantidade de accruals discricionários tende a aumentar a persistência das contas de resultado, outras receitas operacionais e outras despesas operacionais, suavizando estas com maior quantidade de accruals discricionários. Nesse sentido, apesar de não ser possível separar completamente o que é suavização artificial e, portanto, oportunismo do gestor, não é possível afirmar que o aumento da persistência aumenta a qualidade da informação contábil porque é possível que uma parte desses accruals, utilizados para suavizar o lucro, esteja causando o aumento da persistência dessas contas de maneira artificial. 